\title{
ESTUDO DA ENERGÉTICA MODAL PARA EPISÓDIOS DE ZCAS. PARTE I: ANÁLISE OBSERVACIONAL
}

\author{
RENATA WEISSMANN BORGES MENDONÇA e JOSÉ PAULO BONATTI \\ Instituto Nacional de Pesquisas Espaciais (INPE) \\ Centro de Previsão de Tempo e Estudos Climáticos (CPTEC) \\ renata.mendonca@cptec.inpe.br, \\ paulo.bonatti@cptec.inpe.br
}

Recebido Novembro 2007 - Aceito Junho 2008

\begin{abstract}
RESUMO
As trocas horizontais e verticais de energia para um composto de sete episódios de Zona de Convergência do Atlântico Sul (ZCAS), foram estudadas a partir da decomposição em modos normais, considerando-se a partição vertical de energia entre os modos externo e internos, e as interferências entre os modos horizontais de oscilação Rossby, Kelvin, Misto Rossby-Gravidade, Gravidade Oeste e Leste. Um máximo de porcentagem de energia total (aproximadamente 60\%) é observado para os modos internos 4 a 7 , com alturas equivalentes entre 100 e 600 metros, especialmente sobre grande parte da América do Sul central e próximo ao equador, incluindo a região da ZCAS. À medida que a latitude aumenta, a energia é distribuída para os modos mais externos $(\mathrm{n}=1$ a 3$)$. Para a partição horizontal de energia, as maiores contribuições foram obtidas para as auto-interações dos modos Rossby e Kelvin e interações cruzadas Rossby-Kelvin, em todas as categorias de modos verticais, sendo estas últimas responsáveis pelas interferências construtivas de energia na região da ZCAS. As interações entre modos verticais mostraram um aumento da porcentagem de energia dos Baixos Níveis para a Estratosfera, com máxima interferência positiva (negativa) de energia em Altos Níveis (Estratosfera), para os modos internos 4 a 7.
\end{abstract}

Palavras Chave: Energética, Modos Normais, Zona de Convergência do Atlântico Sul (ZCAS).

\begin{abstract}
STUDY OF THE MODAL ENERGETICS FOR SACZ EPISODES. PART I: OBSERVATIONAL ANALYSES

The horizontal and vertical energy exchanges for a composite of seven South Atlantic Convergence Zone (SACZ) episodes were studied by expansion into normal mode functions, with an emphasis on the vertical energy partition between external and internal modes and on the energy interactions within and among various horizontal oscillation modes: Rossby, Kelvin, Mixed Rossby-Gravity and West and East Gravity. A maximum share of the total energy (about 60\%) was found in the 4th to 7 th internal modes at equivalent highs between 100 and 600 meters, especially over large part of the central South America and near the equator including the SACZ region. As the latitude increases, the energy is distributed towards the lower order modes ( $n=1$ to 3$)$. For the horizontal energy partition, the most expressive contributions were obtained for the self-interactions of the Rossby and Kelvin modes and for Rossby-Kelvin cross interactions in all vertical mode categories. The Rossby-Kelvin cross interactions constituted the main process for constructive energy interferences in the SACZ region. The vertical mode interactions indicated that the percentage of total energy increases from low levels to the stratosphere with maximum positive (negative) interferences in high levels (stratosphere), for the 4th to 7th internal modes.
\end{abstract}

Keywords: Energetics, normal mode functions, South Atlantic Convergence Zone (SACZ). 


\section{INTRODUÇÃO}

Durante o verão da América do Sul, mais de 50\% da precipitação anual tanto na região tropical como subtropical é convectiva, com forte variação diurna (Silva Dias et al., 1987). A Zona de Convergência do Atlântico Sul (ZCAS) é uma das características da circulação de verão regional da América do Sul, sendo responsável por grande parte da precipitação anual em regiões economicamente importantes, tais como as regiões Sul e Sudeste do Brasil. Os episódios de ZCAS exemplificam as interações existentes entre a convecção tropical e os sistemas de grande escala, cujos efeitos são refletidos em diversas escalas espaciais e temporais.

A interação entre a convecção tropical e os sistemas de grande escala é caracterizada por processos de conversão de energia. Nos extratrópicos, a fonte primária de energia para os distúrbios atmosféricos de grande escala é a energia potencial disponível zonal, associada ao intenso gradiente meridional de temperatura, sendo o aquecimento diabático devido à liberação de calor latente e ao aquecimento radiativo, fontes secundárias de energia aos sistemas sinóticos de latitudes médias. Nos trópicos, por outro lado, a energia potencial disponível é pequena, devido aos fracos gradientes de temperatura, e a liberação de calor latente é a principal fonte de energia, pelo menos para os distúrbios que se originam na região tropical (Gandu, 1993).

$\mathrm{O}$ ajuste à forçante convectiva ocorre através da propagação de ondas. Essas ondas podem interagir entre si, no regime não linear, influenciando o ajuste à forçante convectiva. Desta forma, uma avaliação conveniente das escalas das forçantes e das ondas geradas fornece uma melhor compreensão do comportamento atmosférico.

Neste sentido, a análise da energia e suas transformações em termos de Funções Modos Normais Tridimensionais (FMN-3D) constituem uma metodologia para o diagnóstico da energética da circulação geral. Os modos normais sobre a esfera, associados às auto-soluções das equações primitivas (linearizadas em torno de um estado básico em repouso) no domínio global permitem uma análise da partição da energia global entre os modos verticais e horizontais nos domínios de número de onda zonal, índice meridional e índice vertical. Nesta abordagem, a solução da estrutura vertical possibilita a análise da energética para cada um dos modos verticais, ou seja, modos externo e internos, separadamente, enquanto na distribuição de energia entre os modos horizontais, os autovalores (modos normais) são classificados em modos gravitacionais (onda de Kelvin e de gravidade) e rotacionais (onda de Rossby e mista).

Portanto, o propósito deste trabalho é apresentar um estudo diagnóstico para eventos de Zona de Convergência do Atlântico Sul, enfatizando a análise energética, principalmente no que se refere à partição de energia entre os modos horizontais de oscilação (ondas de Rossby, Kelvin, misto Rossby-Gravidade e de gravidade inercial, com propagação para leste e para oeste) em função dos modos verticais, a fim de identificar quais modos são dominantes na formação, manutenção e dissipação destes eventos, bem como obter um maior entendimento da estrutura dinâmica da ZCAS, sua formação e efeitos remotos que, eventualmente, possam atuar sobre sua estrutura.

$\mathrm{Na}$ seção 2 são descritos os dados e a metodologia utilizada, bem como os episódios selecionados para este estudo. Os resultados da análise energética são apresentados e discutidos na seção 3. As conclusões são apresentadas na seção 4.

\section{DADOS E METODOLOGIA}

\subsection{Dados}

Os dados utilizados para a análise diagnóstica da energética consistem, basicamente, das análises espectrais obtidas do National Centers for Environmental Prediction (NCEP), com resoluções T126L28 e T170L42, onde Tttt significa truncamento triangular na onda zonal ttt e Lll significa 11 camadas verticais em coordenadas sigma, e horário das 12Z. Essas análises contêm campos espectrais de topografia, logaritmo natural da pressão à superfície, temperatura virtual, divergência horizontal do vento, vorticidade e umidade específica. Estimativas de precipitação diária, provenientes do Global Precipitation Climatology Project (GPCP), foram utilizadas para ilustrar e comparar os campos de precipitação e de partição de energia, associados ao composto dos episódios de ZCAS selecionados.

\subsection{Decomposição em Funções Modos Normais}

Para a análise da partição de energia em modos verticais e horizontais, é feita a recomposição dos dados espectrais no espaço físico, o cálculo das variáveis vento zonal, vento meridional e geopotencial generalizado $\left(\mathrm{P}=\phi-\bar{\phi}(\sigma)+\mathrm{R}_{\mathrm{d}} \overline{\mathrm{T}}(\sigma)\right.$ q, onde $\bar{\phi}(\sigma)$ é o geopotencial hidrostático em relação a $\bar{\phi}(\sigma)$ que é o perfil de temperatura da atmosfera básica, função apenas da coordenada vertical), e então é realizada a decomposição em funções modos normais desses campos atmosféricos, conforme os procedimentos descritos em Kasahara e Puri (1981) e Andrade (1994). Neste caso, os modos verticais são os mesmos que os do modelo de circulação geral do CPTEC (MCGA-CPTEC). A partir daí é calculada a energia em cada modo e sua porcentagem em relação ao total.

Uma representação esquemática dos procedimentos para obter a decomposição das estruturas vertical e horizontal em modos normais é apresentada na Figura 1. 
As equações governantes são linearizadas em torno de um estado básico em repouso e com temperatura média, que é função somente da altura. O método das transformadas é empregado para a decomposição do sistema linearizado nas equações das estruturas horizontal e vertical, acopladas pela profundidade equivalente. A equação da estrutura vertical, juntamente com as condições de contorno, forma um problema de Stürm-Liouville, cujos modos verticais normais são os autovetores, e os autovalores associados são proporcionais à velocidade de fase da onda de gravidade pura (profundidade ou altura equivalente). Estes autovalores fornecem a estrutura horizontal para cada modo vertical normal, ou seja, cada equação da estrutura horizontal está associada a uma profundidade equivalente (autovalor) e a um modo vertical (autovetor). Os modos normais da estrutura horizontal formam uma base completa.

\subsection{Episódios Selecionados}

De acordo com a disponibilidade das análises do NCEP para as resoluções T126L28 e T170L42 e a descrição do boletim Climanálise (2001a, b e c, 2002), foram selecionados 7 episódios de ZCAS para a realização deste estudo, ocorridos nos períodos de janeiro, novembro e dezembro de 2001, e fevereiro de 2002.

As imagens de satélite apresentadas na Figura 2, mostram a temperatura de brilho média para as pêntadas referentes aos períodos (ou parte dos períodos) de atuação destes episódios de

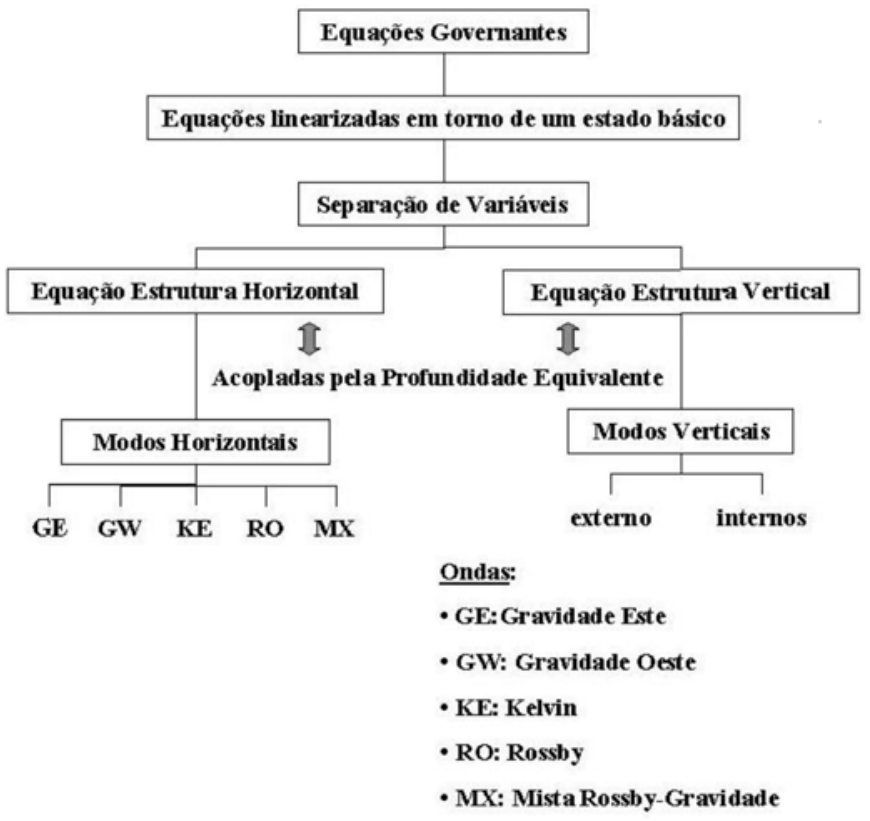

Figura 1 - Procedimento para obter os modos verticais e horizontais. FONTE: Adaptada de Ko et al. (1989).
ZCAS e indicam o posicionamento da banda de nebulosidade associada a cada um dos episódios selecionados. Observa-se, na Figura 2, que o posicionamento da banda de nebulosidade é semelhante para todos os episódios selecionados. Na análise do campo de vento em $850 \mathrm{hPa}$ (Figura não apresentada) verifica-se que estes episódios possuem características sinóticas similares, indicando a possibilidade de se utilizar um composto destes episódios para o estudo da energética modal. Uma breve descrição da técnica utilizada na composição destes episódios é apresentada a seguir.

\subsection{Análise da Partição Modal de Energia}

As equações (1) e (2) representam as contribuições para a energia total em cada modo vertical e horizontal, respectivamente:

$$
P_{n}=\frac{E_{C_{n}}+E_{P_{n}}}{\sum_{n=0}^{N}\left(E_{C_{n}}+E_{P_{n}}\right)} \times 100 \%
$$

onde $\mathrm{Ec}_{\mathrm{n}}, \mathrm{Ep}_{\mathrm{n}}$, representam, respectivamente a energia cinética e a energia potencial disponível associada a cada modo vertical $\mathrm{n}$;

$$
\mathrm{PE}_{w}=\frac{\sum_{n=n_{1}}^{n_{2}} E_{w}}{\sum_{n=1}^{M} E_{T n}} \times 100 \%
$$

com

$$
\mathrm{E}_{\text {Tn }}=\mathrm{E}_{\text {Tsoma }}+\mathrm{E}_{\text {Tint }} \text {, }
$$

e

$$
\begin{aligned}
& \mathrm{E}_{\text {Tint }}=\mathrm{ET}_{\mathrm{RBKV}}+\mathrm{ET}_{\mathrm{RBMX}}+\mathrm{ET}_{\mathrm{RBGO}}+ \\
& \mathrm{ET}_{\mathrm{RBGE}}+\mathrm{ET}_{\mathrm{KVMX}}+\mathrm{ET}_{\mathrm{KVGO}}+\mathrm{ET}_{\mathrm{KVGE}}+ \\
& \mathrm{ET}_{\mathrm{MXGO}}+\mathrm{ET}_{\mathrm{MXGE}}+\mathrm{ET}_{\mathrm{GOGE}},
\end{aligned}
$$

em que $\mathrm{PE}_{\mathrm{w}}$ representa a porcentagem da energia total do modo horizontal $\mathbf{w}$ em relação a todos os modos, incluindo as interações entre eles, contida na categoria de modos verticais considerada. $\mathrm{E}_{\mathrm{wn}}, \mathrm{E}_{\text {Tsoma }}$ e $\mathrm{E}_{\text {Tint }}$ são, respectivamente, as energias totais de cada modo horizontal w, ou seja, Rossby ( $\left.\mathrm{E}_{\mathrm{TRB}}\right)$, Kelvin $\left(\mathrm{E}_{\mathrm{TKV}}\right)$, Mista Rossby-Gravidade $\left(\mathrm{E}_{\mathrm{TMX}}\right)$, Gravidade Oeste $\left(\mathrm{E}_{\mathrm{TGO}}\right)$ e Gravidade Leste $\left(\mathrm{E}_{\mathrm{TGE}}\right)$, a soma de todos os 
modos horizontais $\left(\mathrm{E}_{\mathrm{TRB}}+\mathrm{E}_{\mathrm{TKV}}+\mathrm{E}_{\mathrm{TMX}}+\mathrm{E}_{\mathrm{TGO}}+\mathrm{E}_{\mathrm{TGE}}\right)$ e as interações entre os pares de modos horizontais indexados, para um dado modo vertical $\mathrm{n}$. Integrados globalmente, os produtos cruzados se anulam (ortogonalidade das Funções de Hough), entretanto, localmente, estes produtos podem ser interpretados como interferência construtiva (valores positivos) ou destrutiva (valores negativos) de energia, resultante da interação entre os modos que produzem o produto. $\mathrm{O}$ limiar $\mathrm{M}$ da somatória no denominador de (3) denota o número de modos verticais considerados, neste caso, $\mathrm{M}=12$ (14) para 28 (42) níveis verticais.
A área definida para a análise energética é mostrada na Figura 3. O estudo é realizado para a América do Sul, enfatizando-se a região de atuação da ZCAS. A região média de atuação do composto de ZCAS foi definida a partir do campo composto de vento horizontal em $850 \mathrm{hPa}$ (Figura não apresentada), considerando-se a área de confluência dos ventos associada a ZCAS. O segmento AB indica o eixo médio da confluência em $850 \mathrm{hPa}$, que coincide com a banda de nebulosidade associada ao composto de ZCAS.

O estudo baseia-se no cálculo diário da partição de energia entre os modos normais verticais e horizontais, para
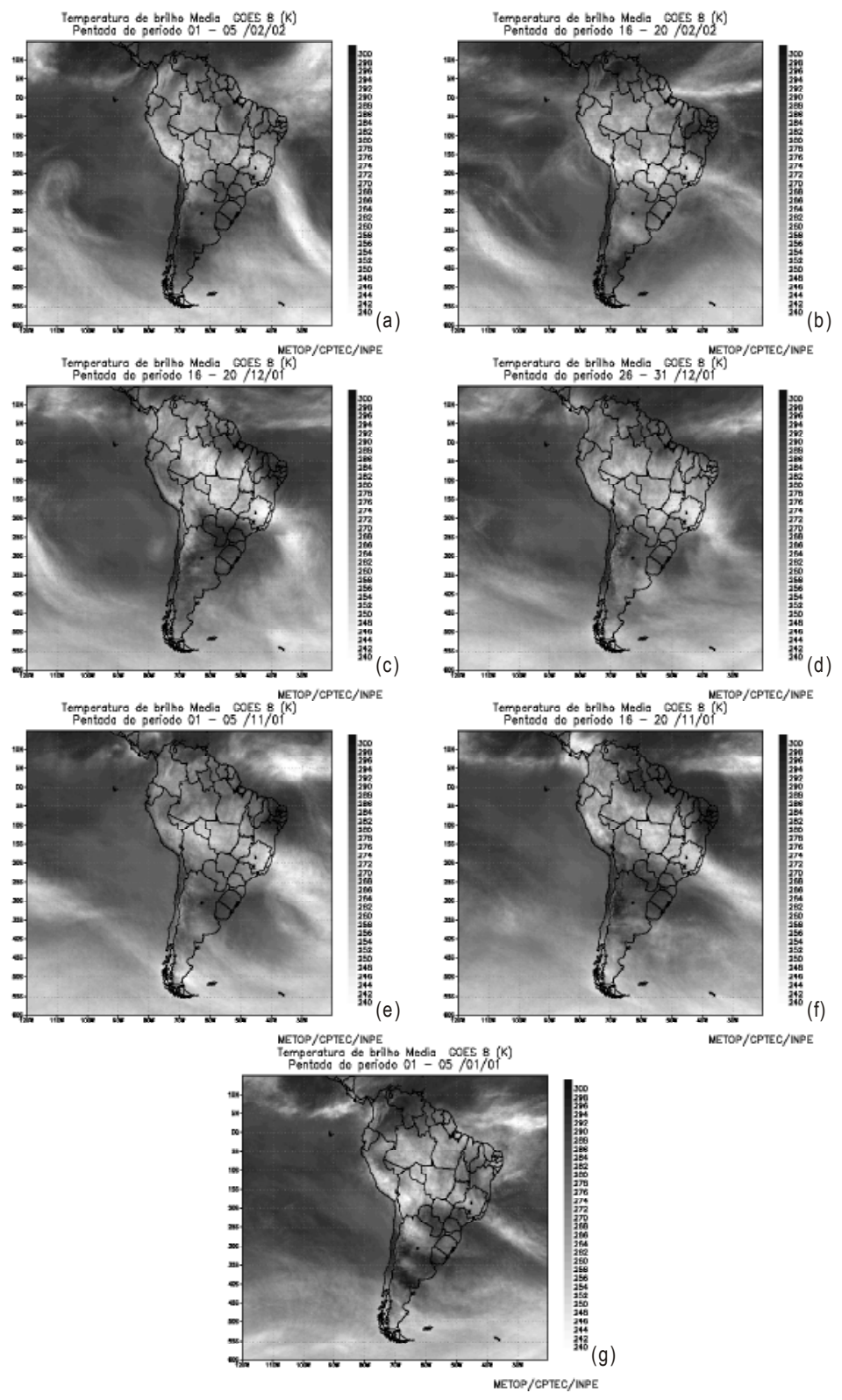

Figura 2 - Temperatura de Brilho Média para pêntadas referentes aos episódios de ZCAS selecionados. FONTE: Metop/CPTEC/INPE. 


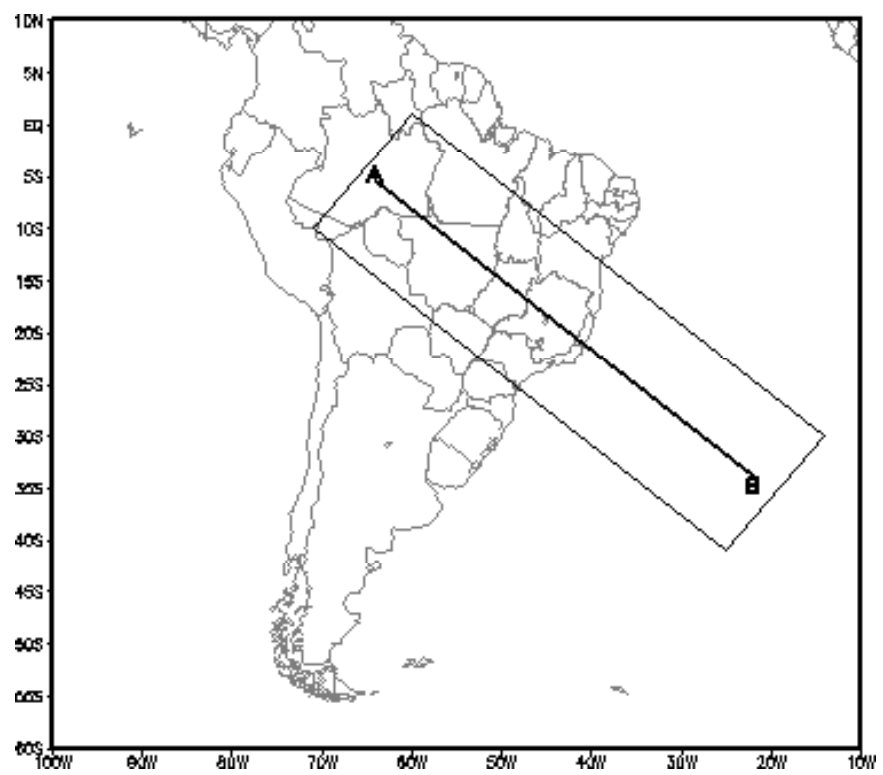

Figura 3 - Região média de atuação do composto de ZCAS, definida para a partição modal vertical de energia sobre a América do Sul.

cada episódio descrito na seção 2.3. Para cada episódio, foi considerado um intervalo de aproximadamente 10 dias, iniciando/terminando 2 a 3 dias antes/depois do período de atuação da ZCAS, considerando as análises do NCEP das $12 \mathrm{Z}$ para as datas selecionadas e resoluções T126L28 e T170L42.

Os resultados são apresentados para o composto dos episódios de ZCAS selecionados, considerando apenas os dias em que estes eventos estiveram efetivamente atuando. $O$ cálculo do composto de ZCAS é baseado na média aritmética dos 7 episódios de ZCAS, considerando-se as análises válidas para o período de atuação destes eventos. Inicialmente, os campos médios (média no tempo), $\chi_{n}=\sum_{k=1}^{K} \frac{\chi_{n k}}{K}$, foram obtidos para cada episódio de ZCAS $(\mathrm{n}=1, \ldots, 7)$, onde $\chi_{n k}$ representa o campo de vento, a ser composto, referente ao dia $\mathrm{k}(\mathrm{k}=1, \ldots, \mathrm{K})$ e $\mathrm{K}$ o número de dias em que o episódio $n$ esteve atuando; calculou-se então a média aritmética dos campos médios para os 7 episódios de ZCAS $\chi=\sum_{n=1}^{7} \frac{\chi_{n}}{7}$, obtidos anteriormente. $\chi$ representa, desta forma, um campo composto, referenciado aqui como composto de ZCAS. Esta técnica de composição foi empregada considerando-se a semi-estacionariedade dos fenômenos de ZCAS, o que possibilitou o cálculo da média temporal $\chi_{n}$.

A avaliação dos resultados, apresentada na seção 3 a seguir, foi dividida basicamente em quatro etapas: (i) análise dos campos de porcentagem de energia total em função das categorias de modos verticais; (ii) identificação das fontes e sumidouros de energia; (iii) análise da partição de energia total (\%) dos modos horizontais e das interações entre os pares de modos horizontais em função das categorias de modos verticais; e (iv) análise da interação de energia total (\%) entre os modos verticais em diferentes níveis de pressão.

\section{RESULTADOS E DISCUSSÕES}

\subsection{Partição de Energia entre os Modos Verticais}

A estrutura atmosférica vertical em termos de modos normais é dependente do modelo (Silva Dias e Bonatti, 1986). A Figura 4 mostra as auto-funções e as profundidades equivalentes (autovalores) dos 8 primeiros modos verticais, para uma atmosfera padrão de 28 e 42 camadas, respectivamente. Os modos externos para os modelos de 28 e 42 níveis $\left(\mathrm{H}_{1}=9805 \mathrm{~m} \mathrm{e}_{1}=9820 \mathrm{~m}\right)$, representados nos painéis (a) e (c), respectivamente, apresentam estrutura vertical quase independente da altura e são referidos como modo barotrópico equivalente. As estruturas verticais dos modos internos tornam-se mais complicadas e confinadas aos níveis mais baixos, para $\mathrm{n}>14$ (não apresentados). Estes modos são referidos como modos baroclínicos. Em acordo com o trabalho de Silva Dias e Bonatti (1986), destaca-se o modo $\mathrm{n}=5$, com alturas equivalentes de $284 \mathrm{~m}$ e $342 \mathrm{~m}$, respectivamente para 28 e 42 níveis, que apresentam máximos em torno de 800 e $200 \mathrm{hPa}$, e um zero em torno de $400 \mathrm{hPa}$. Este modo detém a maior parte da energia nos trópicos, principalmente próximo à regiões de intensa atividade convectiva. $\mathrm{O}$ modo externo $\left(\mathrm{H}_{1}=\right.$ $9805 \mathrm{~m} \mathrm{e} \mathrm{H}_{1}=9820 \mathrm{~m}$ ) é dominante na região do cinturão de altas pressões.

Uma análise preliminar dos resultados para as resoluções T062L28 (não apresentados) e T126L28, mostrou que os padrões encontrados são bastante semelhantes entre si, sugerindo que os impactos do aumento de resolução horizontal de aproximadamente $200 \mathrm{~km}$ para $100 \mathrm{~km}$ não são tão significativos, quanto aqueles devido ao aumento na resolução vertical de 28 para 42 níveis. Desta forma, serão apresentados neste estudo apenas os resultados para as resoluções T126L28 e T170L42.

A porcentagem de energia total dos modos verticais para uma secção vertical ao longo da posição média do composto de ZCAS (segmento AB, indicado na Figura 3) é apresentada na Figura 5. Observa-se que, em ambas as resoluções, os modos internos 4 a 7 com alturas equivalentes entre 600 e 100 metros são os que apresentam maior concentração de energia. Um máximo secundário de energia é verificado para os três primeiros modos verticais $(n=1-3)$, com o modelo de alta resolução (T170L42) indicando valores ligeiramente mais altos. Desta forma, a maior concentração de energia ao longo da secção vertical da ZCAS ocorre nos 7 primeiros modos verticais, como pode ser visto mais detalhadamente na Figura 6. Além disso, nota-se uma maior dominância dos modos mais externos (1 a 3) sobre o oceano em latitudes médias, e dos modos mais internos (4 a 7) sobre o continente na região tropical.

A Figura 6 mostra a partição de energia do modelo nas formas cinética (ECn) e energia potencial (EPn), bem como a contribuição percentual de energia total em função dos modos 
verticais (profundidade equivalente), média na área indicada na Figura 3. Novamente, é possível notar que a partição vertical de energia está concentrada no modo interno $\mathrm{n}=5\left(\mathrm{H}_{5}=284 \mathrm{~m}\right.$; $342 \mathrm{~m})$. Um máximo secundário de energia pode ser também observado no segundo modo vertical, com altura equivalente $\mathrm{H}_{2}$ em torno de $4856 \mathrm{~m}$ e $5085 \mathrm{~m}$, respectivamente para 28 e 42 níveis. Além disso, nota-se que a energia cinética parece ser, em grande parte, representada pelos modos verticais de ordem menor ( $n=1$ a 3 ), enquanto que a energia potencial no modo externo é mínima, com um pico acentuado no quinto modo, o qual determina a dominância na distribuição da porcentagem. Estes resultados estão de acordo com os trabalhos de Kasahara e Puri (1981) e Silva Dias e Bonatti (1985, 1986), exceto que o máximo secundário de energia foi verificado para o modo externo (barotrópico), o que pode ser explicado pelas diferenças nos modelos e cenários meteorológicos utilizados nos estudos, uma vez que esta metodologia empregando modos normais é dependente do modelo.

De acordo com a partição vertical de energia indicada nas Figuras 5 e 6, serão consideradas três categorias de modos verticais: (I) $n=1$ a 3 , com $\mathrm{Hn}$ acima de $600 \mathrm{~m}$; (II) $\mathrm{n}=4$ a 7, com Hn entre 100 e $600 \mathrm{~m}$; e (III) n=8 a 12 (14, para 42 níveis), com Hn entre 10 e $100 \mathrm{~m}$, a fim de simplificar a análise dos próximos resultados. A primeira categoria é definida como a categoria do modo externo e dos dois primeiros modos internos, desde que os zeros das estruturas verticais para $\mathrm{n}=1$ a 3 só aparecem em altos níveis (Figuras 4a e 4c). As categorias II e III representam as categorias de modos internos.

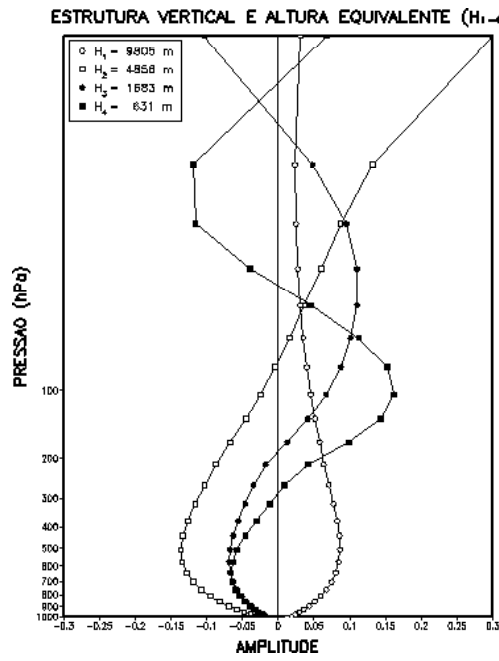

(a)



(c)

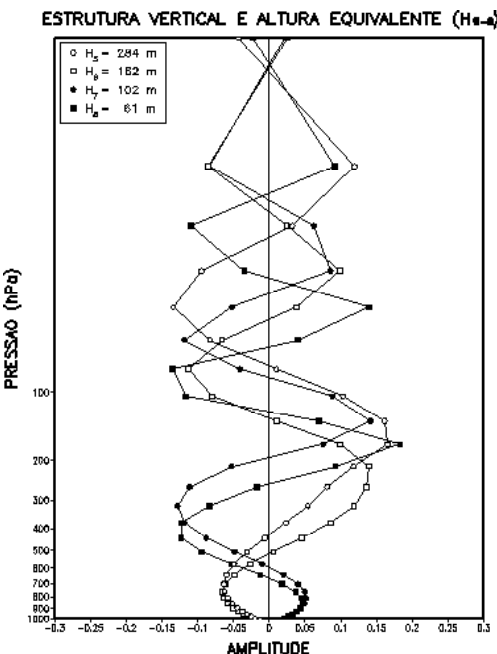

(b)

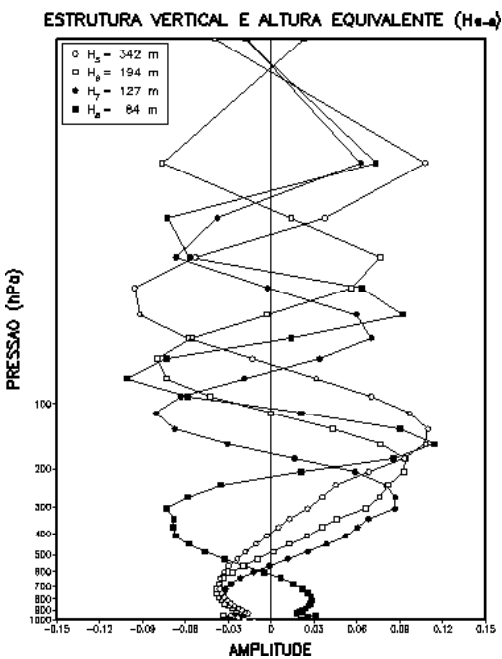

(d)

Figura 4 - Estrutura Vertical e Altura Equivalente (m) dos 8 primeiros modos verticais, Modos 1-4 (a esquerda) e Modos 5-8 (a direita), para os modelos com: 28 níveis (a) e (b) e 42 níveis (c) e (d), respectivamente. 
Os campos de porcentagem de energia total para as análises do NCEP, T126L28 e T170L42, são apresentados na Figura 7. Os padrões observados nos painéis (a) a (f) são bastante semelhantes para ambas as resoluções, notando-se apenas algumas diferenças quantitativas. Os valores apresentados pela análise T170L42 são ligeiramente inferiores àqueles da análise T126L28, para as categorias I e II; o inverso é observado para a categoria III, ressaltando o impacto do aumento da resolução vertical, de 28 para 42 níveis.

No caso da categoria I, nota-se que a energia dos modos verticais 1 a 3 é mais significativa em latitudes mais altas (valores em torno de 50-60\%), diminuindo em direção ao equador, o que pode estar associada à influência do jato subtropical nesta faixa de latitude, uma vez que este pode ser descrito por ondas de Rossby longas. Os modos 4 a 7 (categoria II) apresentam valores maiores de energia em grande parte da faixa central da América do Sul e próximo ao equador, incluindo a região de atuação da ZCAS. Nota-se que estes núcleos de alta porcentagem de energia (cerca de $60 \%$ ) estão situados em

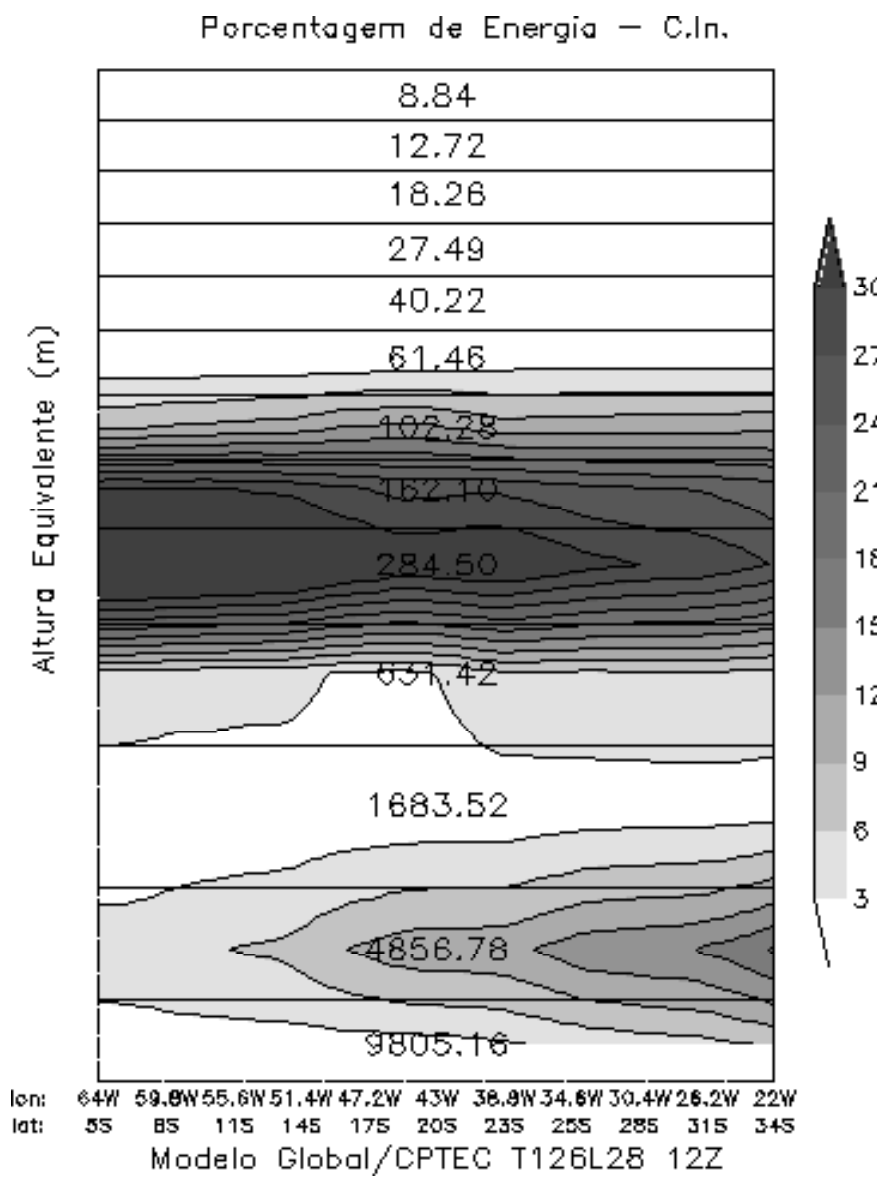

(a) regiões convectivamente ativas e estão em concordância com o posicionamento da banda de nebulosidade associada a ZCAS (Figura 8). Os modos verticais 4 e 5 são aqueles mais excitados pelo aquecimento convectivo, na região tropical (Puri, 1983). A categoria III mostra um padrão similar àquele da categoria I, embora com porcentagens menores de energia.

Randel e Stanford (1985a,b) estudaram a estrutura e energética das ondas de escala média durante o verão do Hemisfério Sul, e verificaram que estas ondas resultam de instabilidades baroclínicas e possuem um ciclo de vida bem definido, no qual se observa um máximo crescimento baroclínico da onda precedendo (em um dia) o pico de máxima energia e um máximo decaimento barotrópico da onda após dois dias deste pico de energia. Os resultados das Figuras 7 e 8 , juntamente com o fato de que a maior parte da energia total está na forma cinética (Figura 6), sugerem que, no caso dos episódios de ZCAS, a estabilidade barotrópica ou o decaimento barotrópico da onda (sistema frontal responsável pela formação da zona de convergência), é parcialmente responsável por este

\section{Porcentagem de Energia - C.In.}

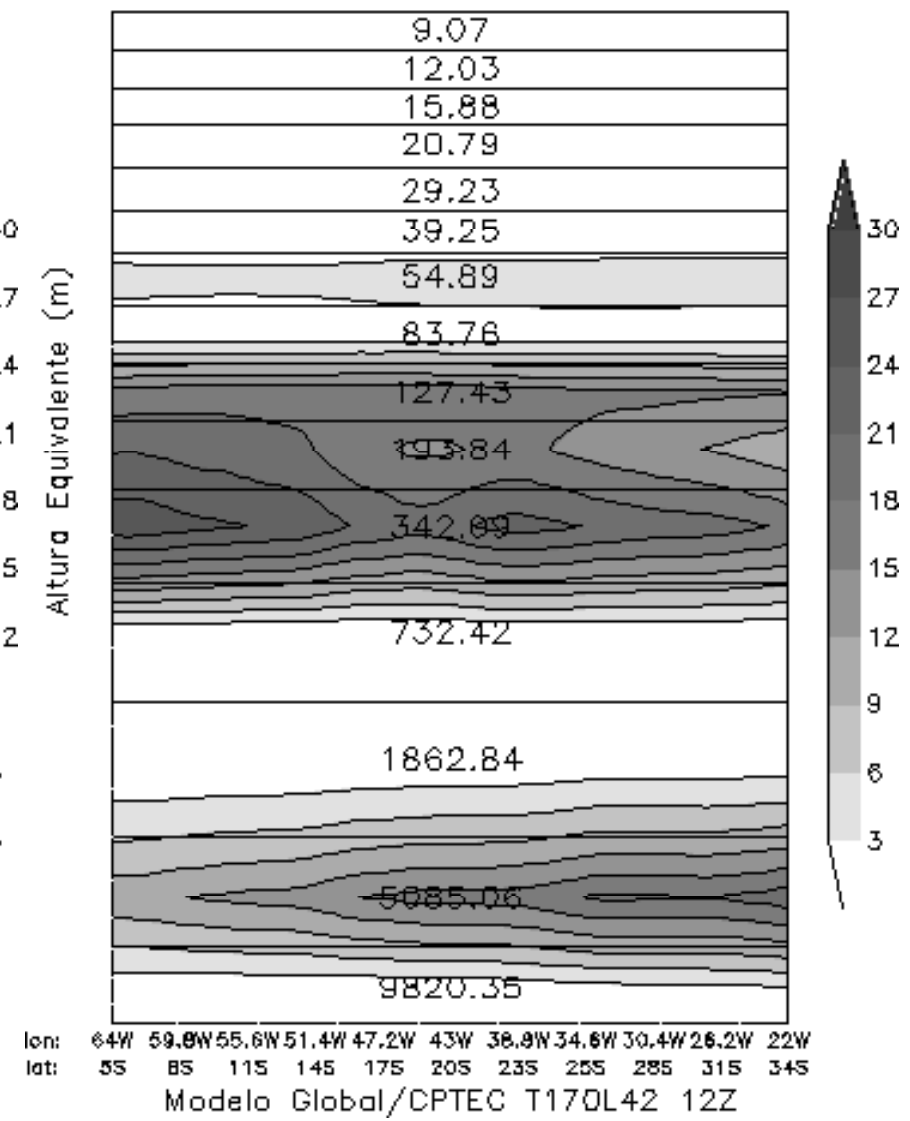

(b)

Figura 5 - Porcentagem de energia total (sombreado) e altura equivalente (metros, valores indicados sobre as linhas horizontais), secção vertical ao longo da posição média da ZCAS (segmento AB, Fig. 3), análise NCEP 12Z: (a) T126L28 e (b) T170L42. 


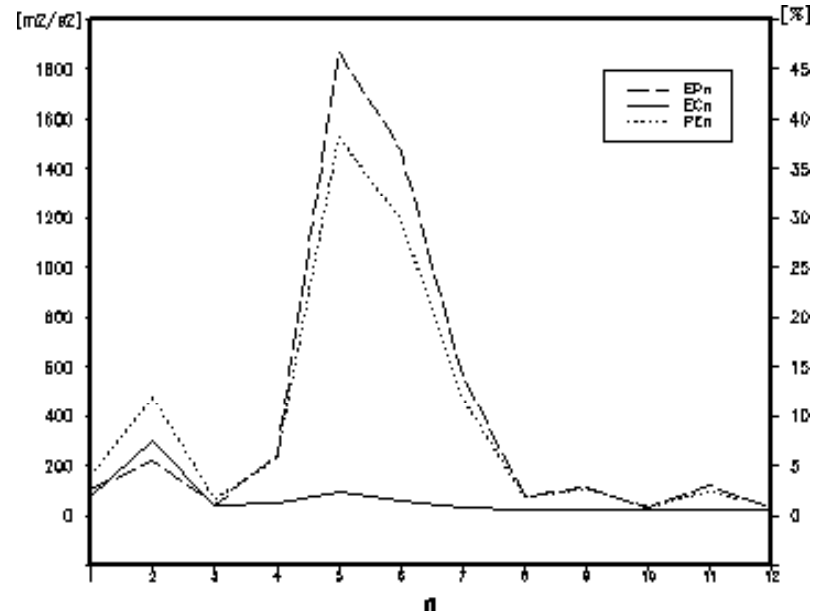

(a)



(b)

Figura 6-Energia Cinética $\left(\mathrm{m}^{2} / \mathrm{s}^{2}\right)$ - ECn, Energia Potencial Disponível $\left(\mathrm{m}^{2} / \mathrm{s}^{2}\right)$ - EPn e Porcentagem de Energia Total - PEn (linhas sólida, tracejada e pontilhada, respectivamente) em função do modo vertical n, para a região ilustrada na Fig. 3, análise NCEP: (a) T126L28 e (b) T170L42.

máximo de energia cinética nos modos mais externos, resultante da intensificação do escoamento zonal e, portanto, do aumento de energia cinética zonal.

Uma avaliação dos perfis verticais das fontes e sumidouros de calor (Figuras não apresentadas), obtidas a partir do resíduo (taxa de aquecimento/resfriamento diabático) da equação de balanço termodinâmico (Mendonça, 2005), indicou que fontes de calor mais intensas estão localizadas entre os níveis de 700 e $150 \mathrm{hPa}$. Na Figura 9 são apresentadas as fontes e sumidouros de calor para o composto de episódios de ZCAS mediados na vertical entre estes níveis. Observa-se fontes de calor (com núcleos da ordem de $6 \mathrm{~K} /$ dia) sobre as regiões convectivas, ZCAS e Zona de Convergência Intertropical (ZCIT), e sumidouros de calor sobre a região dos Andes. Em ambas as resoluções, os padrões observados não apresentam diferenças significativas e concordam com os núcleos de máxima porcentagem de energia verificados na Figura 7.

\subsection{Partição de Energia entre os Modos Horizontais}

A análise energética das estruturas horizontais indica, que em ambas as resoluções T126L28 e T170L42, as contribuições para a porcentagem de energia são bem distribuídas entre as três categorias de modos verticais, destacando-se os modos Rossby e Kelvin como os principais determinantes do padrão espacial de energia (Figuras 10-12). Quantitativamente, observa-se que os valores foram ligeiramente maiores para os modos verticais 1 a 3 e 8 a 14 na resolução T170L42, enquanto a categoria II (modos 4 a 7), que detém as maiores porcentagens de energia, apresenta valores relativamente inferiores aos obtidos na resolução T126L28. Isto deve estar associado ao maior detalhamento da discretização vertical, quando são considerados 42 níveis verticais.

Na Figura 10a,b, observa-se que as maiores porcentagens de energia estão localizadas nas latitudes mais altas, diminuindo na região central da América do Sul, incluindo a região da ZCAS e voltando a aumentar ao norte do equador. Estas máximas porcentagens de energia em latitudes mais altas estão basicamente associadas ao modo Rossby (Figura 10c,d) e podem ser interpretadas como uma resposta ao aquecimento equatorial, que em concordância com o trabalho de Kasahara e Silva Dias (1986), são mais fortes e barotrópicas equivalente em latitudes médias e altas, e geradas principalmente pela conversão de energia dos modos internos para o modo externo. Kasahara e Tanaka (1989) também analisaram a distribuição espectral de energia para os modos horizontais (Kelvin e Rossby) e verticais (barotrópico e baroclínicos internos) associados ao problema da instabilidade baroclínica e verificaram que a maior quantidade de energia se encontra nos modos rotacionais (Rossby) do modo externo e que a instabilidade baroclínica nos movimentos de oeste pode gerar o modo externo efetivamente. Seus resultados indicam também, que os modos Kelvin e Gravidade não desempenham um papel muito significativo na instabilidade baroclínica atmosférica. Próximo ao equador, e especialmente na região da ZCAS (regiões convectivamente ativas), as maiores contribuições de energia devem-se ao modo Kelvin (Figura 10e,f).

Outro aspecto importante observado das Figuras 6 e 10 é que a porcentagem da energia nos modos da Categoria I sobre a região da ZCAS é maior para a resolução T170L42, reforçando o fato de que as conversões de energia dos modos internos (que requerem uma maior resolução vertical) para o 



(a)

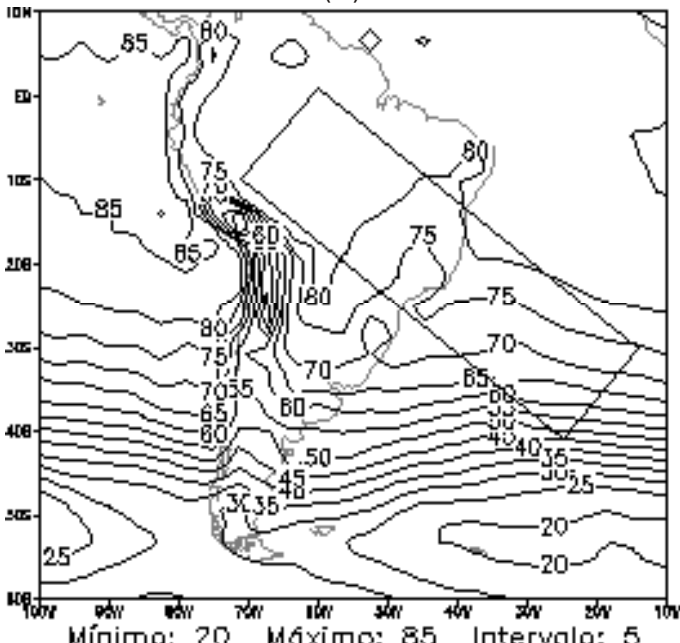

(b)

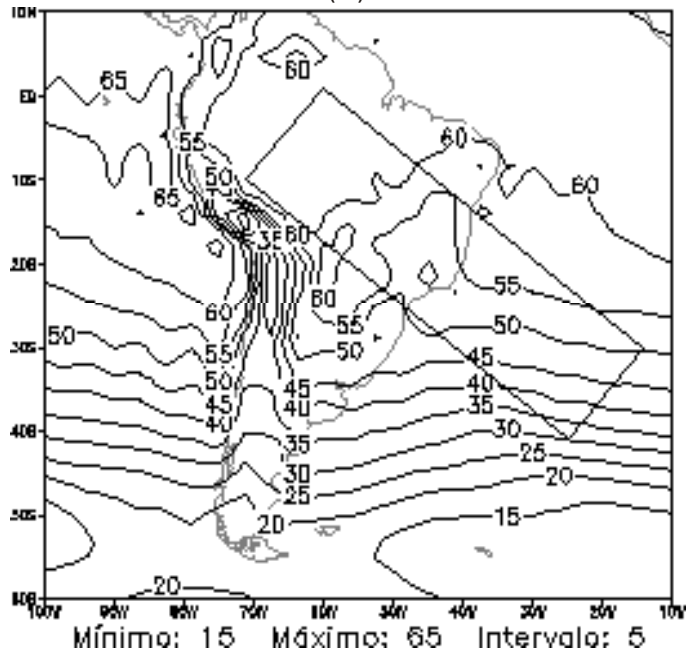

(d)

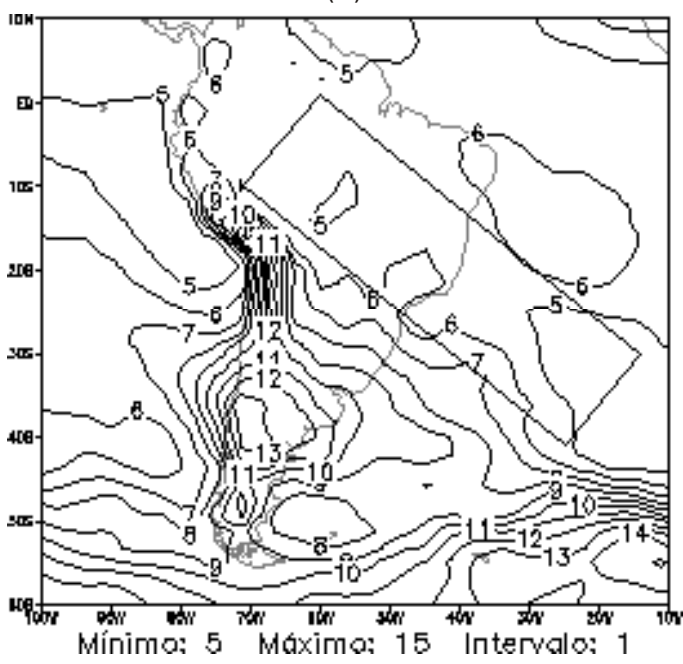

(e)

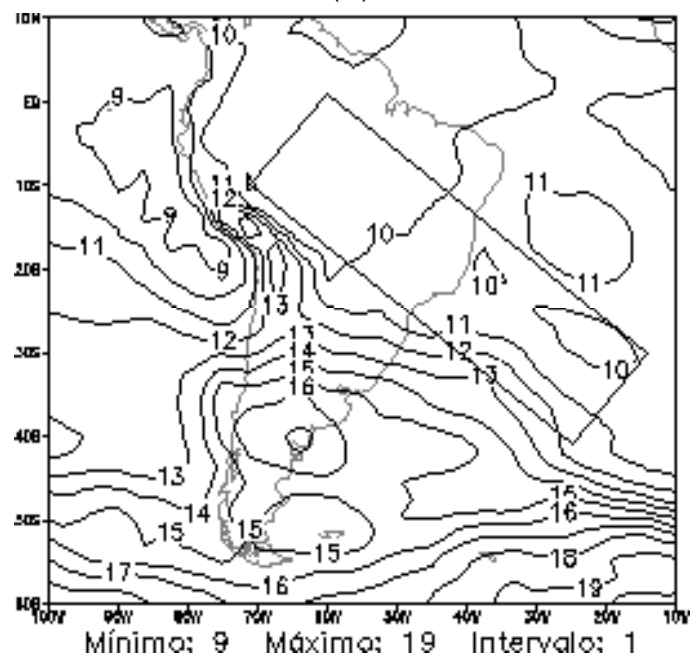

(f)

Figura 7 - Energia Total (\%), análise NCEP T126L28 (a esquerda) e T170L42 (a direita): (a) e (b) modos verticais 1 a 3; (c) e (d) modos verticais 4 a 7 ; e (e) e (f) modos verticais 8 a 12 (8 a 14, para T170L42). 




Figura 8 - Estimativas de precipitação total ( $\mathrm{mm} / \mathrm{dia})$, dados GPCP, para o composto de ZCAS.

modo externo na região convectiva podem ser importantes para a excitação das ondas com estruturas verticais mais barotrópicas. Essas ondas barotrópicas, por sua vez, são importantes para o desenvolvimento dos padrões globais de teleconexões. No trabalho de Grimm e Silva Dias (1995) verifica-se claramente, que a fonte de calor gerada pela atividade da ZCAS tem um papel importante no estabelecimento do padrão Euro-Ásia, por meio da propagação de energia de ondas de Rossby barotrópicas, que cruzam o equador por meio do duto de oeste do Atlântico. Estes resultados, portanto, têm algumas implicações importantes para a previsão climática, uma vez que sugerem que a resolução vertical pode ser importante para a correta representação nos modelos, desses padrões de teleconexões associados com a ZCAS.

Para os modos verticais 4 a 7 (Figura 11a,b), o somatório de energia de todos os modos horizontais mostra máximos de porcentagem de energia confinados equatorialmente, com valores acima de $100 \%$, o que indica uma região de interação entre os modos horizontais, como será apresentado posteriormente. As porcentagens de energia diminuem com o aumento da latitude, sendo que o padrão espacial observado na região equatorial é basicamente determinado pelo modo Kelvin (Figura 11c,d). O modo Rossby (Figura 11e,f) apresenta maiores contribuições na região central da América do Sul e, particularmente, sobre a região Amazônica e ZCAS.

O campo de porcentagem de energia da soma de todos os modos horizontais para a categoria de modos verticais 8 a 12 (14, para T170L42), apresenta padrões semelhantes aos observados para a categoria I, com máximos de energia total em latitudes médias e altas associados às ondas de Rossby e máximos confinados equatorialmente associados ao modo Kelvin (Figura 12). Particularmente, na região da ZCAS, observa-se contribuições significativas de energia do modo Rossby (Figura $12 \mathrm{c}, \mathrm{d})$, com padrões espacialmente bem definidos, ao contrário do padrão mais zonal verificado para os modos verticais 1 a 3 (Figura 10c,d). Nota-se ainda que, neste caso, a análise com resolução T170L42 apresenta valores significativamente maiores, comparados àqueles da resolução T126L28.

Em todas as categorias de modos verticais, as autointerações dos modos horizontais Misto Rossby-Gravidade, Gravidade Oeste e Gravidade Leste apresentaram valores desprezíveis de porcentagem de energia na região de interesse deste estudo e, portanto, não são apresentados.

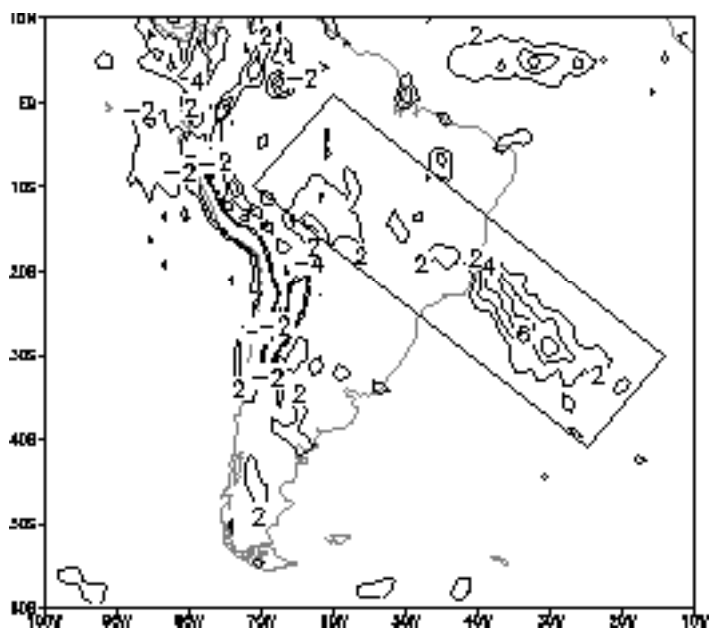

(a)

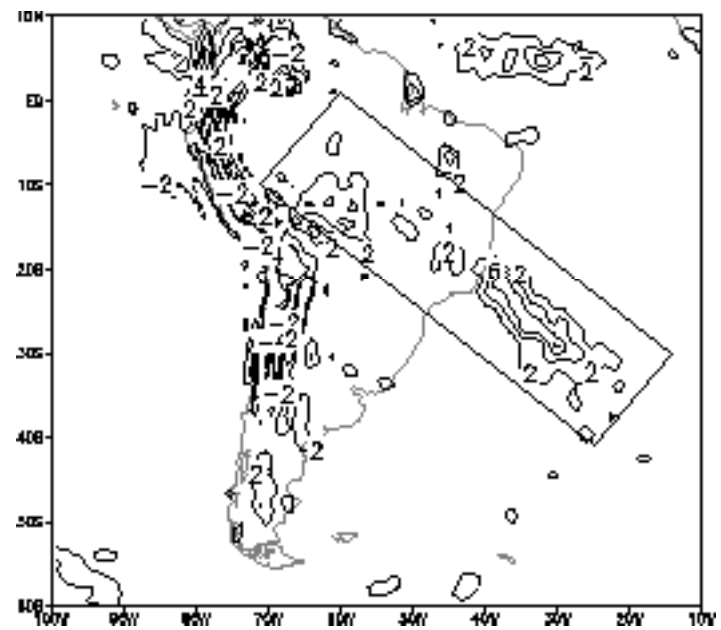

(b)

Figura 9- Fontes e sumidouros de calor (K/dia) para o composto de ZCAS, média entre os níveis 700 hPa e 250 hPa, análises NCEP: (a) T126L28 e (b) T170L42. 
As interações entre pares de modos horizontais indicam contribuições relevantes para a energética nas duas primeiras categorias de modos verticais, 1 a 3 e 4 a 7 . Para a categoria III, os resultados são pouco expressivos, com pequenas contribuições apenas sobre o continente na região de interesse. A porcentagem de energia da soma de todas as interações entre as estruturas horizontais (resíduo) para as resoluções T126L28 e T170L42 mostra que as maiores interações ocorreram na categoria II, que inclui os modos verticais 4 a 7 . Os principais resultados são apresentados nas Figuras 13-15 a seguir.

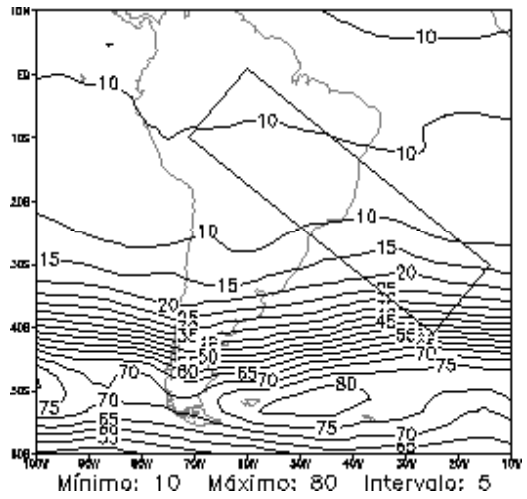

(a)

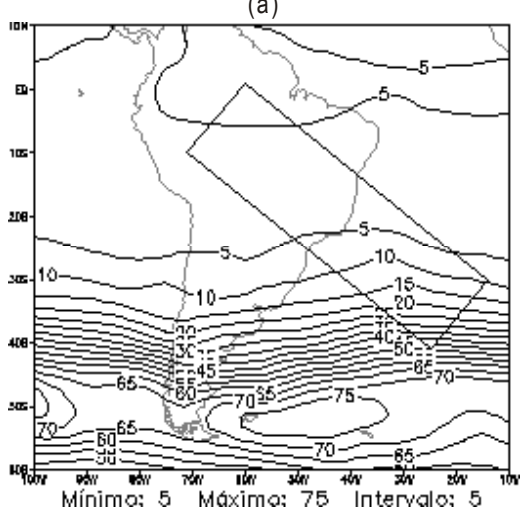

(c)

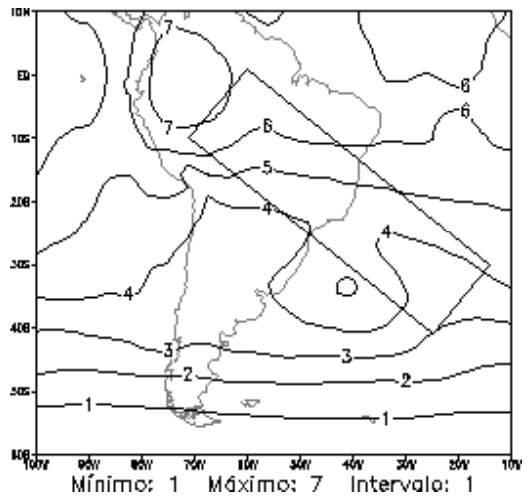

(e)
A interação total entre os modos horizontais (resíduo) para os modos verticais 1 a 3, representada pela Figura 13a,b, indica duas faixas de interferência destrutiva entre os modos horizontais, uma provocando diminuição de energia na região equatorial, e outra, com núcleos máximos negativos ao sul de $40^{\circ} \mathrm{S}$; entre $10^{\circ} \mathrm{S}$ e $40^{\circ} \mathrm{S}$, nota-se uma região de interferência construtiva, provocando aumento ou criação de energia na América do Sul central e, especialmente, sobre a região da ZCAS.

As interações entre os modos horizontais Rossby e Kelvin (Figura 13c,d) são as que mais contribuem para o

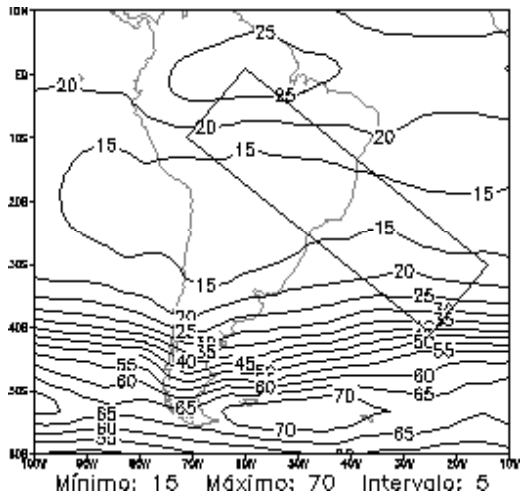

(b)

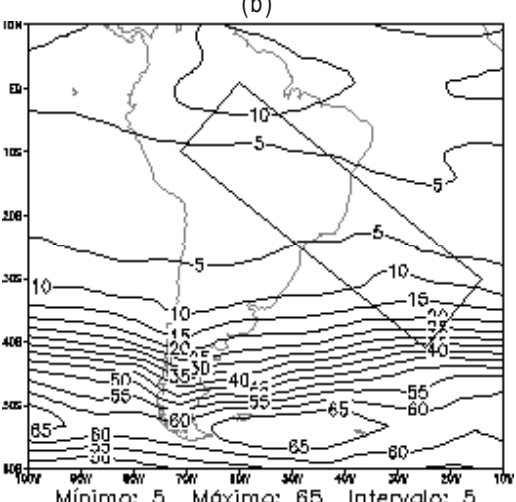

(d)

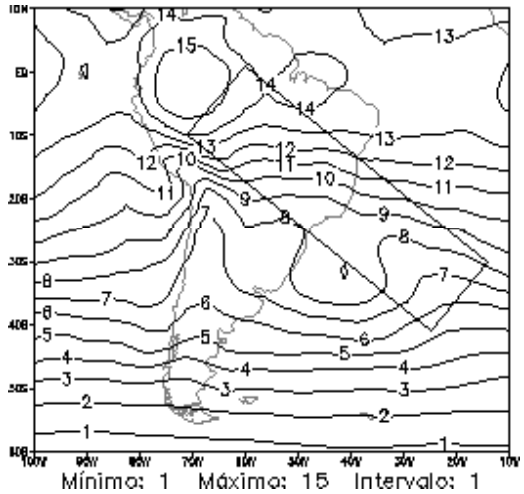

(f)

Figura 10 - Energia Total (\%) dos modos horizontais referente aos modos verticais 1 a 3, para a análise NCEP T126L28 (a esquerda) e T170L42 (a direita): (a) e (b) Soma; (c) e (d) Rossby; (e) e (f) Kelvin. 
padrão observado nos painéis (a) e (b), com interferências construtivas de energia bem definidas na posição média do composto de ZCAS, e núcleos máximos em $40^{\circ} \mathrm{S}$. Valores máximos de interferências negativas entre modos horizontais são encontrados em torno do equador. Estes resultados vão de encontro àqueles do trabalho de Raupp e Silva Dias (2002), que mostram que as interações entre os modos Rossby e Kelvin têm um papel importante na propagação inter-hemisférica de energia. Seus resultados indicam mecanismos de instabilidade

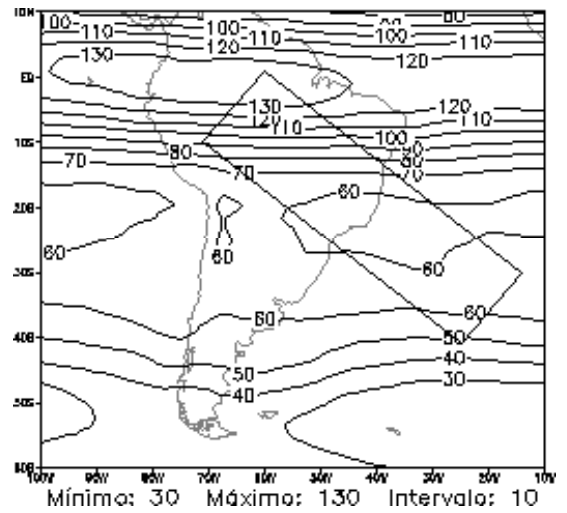

(a)

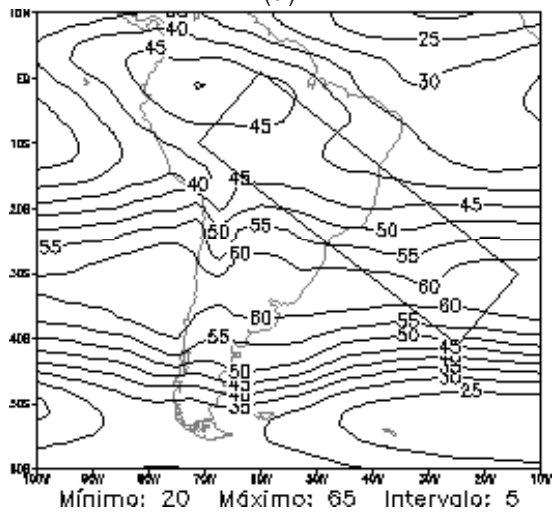

(c)

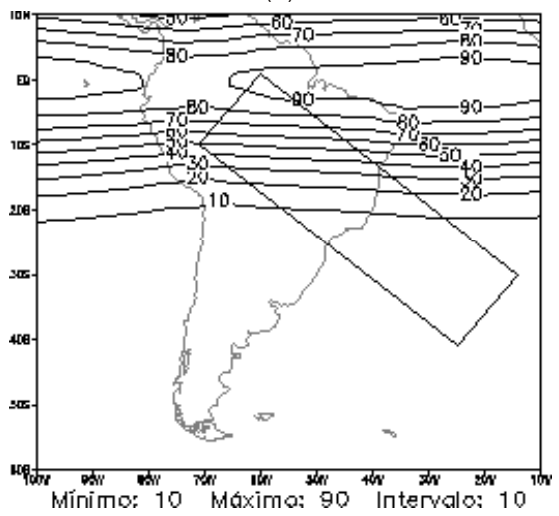

(e) do escoamento zonal de oeste, excitados pela forçante térmica na região equatorial através de ondas de Kelvin, cuja propagação têm um impacto expressivo sobre a propagação inter-hemisférica da energia, além de modular a propagação inter-hemisférica da energia associada às ondas de Rossby.

Na Figura 13e,f, as interações entre os modos Rossby e Misto Rossby-Gravidade indicam uma alternância de interferências construtivas e destrutivas de energia em relação às faixas de latitudes, com núcleos negativos bem configurados

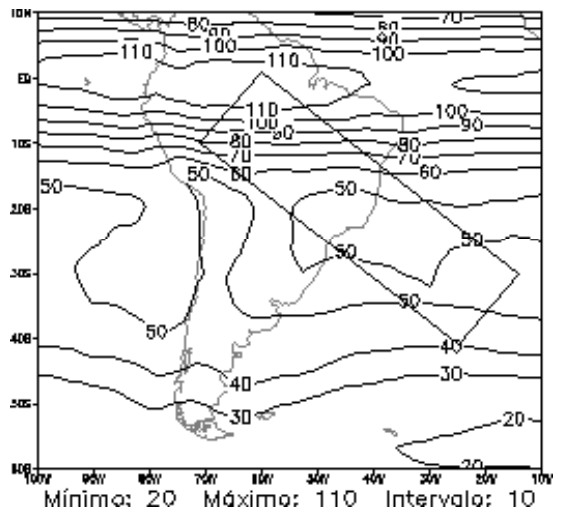

(b)



(d)

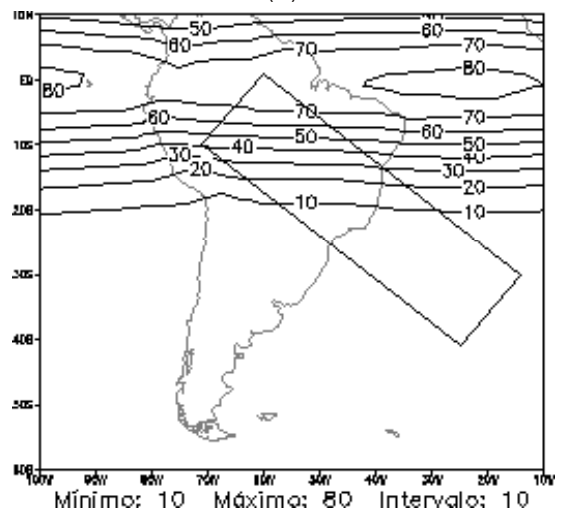

(f)

Figura 11 - Energia Total (\%) dos modos horizontais referente aos modos verticais 4 a 7, para a análise NCEP T126L28 (a esquerda) e T170L42 (a direita): (a) e (b) Soma; (c) e (d) Rossby; (e) e (f) Kelvin. 
em torno de $35^{\circ} \mathrm{S}$, apresentando máxima diminuição de energia na região da ZCAS sobre o oceano. Um núcleo de máxima interferência construtiva de energia é verificado sobre a Região Nordeste do Brasil, determinando um padrão dipolo em torno de $30^{\circ} \mathrm{W}$. Embora estes valores sejam de uma ordem de grandeza inferior, suas contribuições são relevantes na região de interesse deste estudo, especialmente sobre o oceano.

As Figuras 14 e 15 ilustram as principais interações entre os modos horizontais para os modos verticais 4 a 7 . Os padrões



(a)

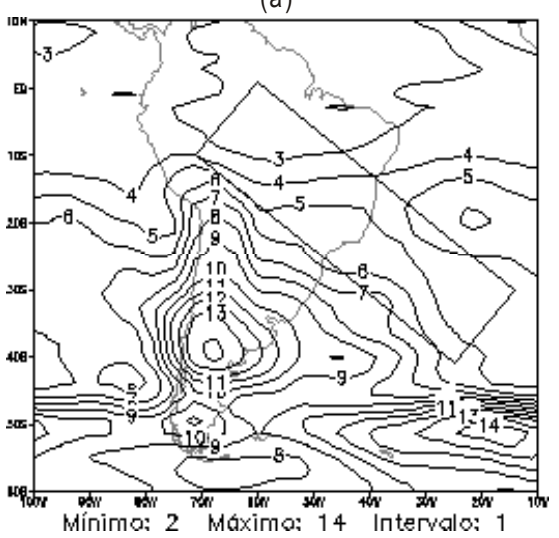

(c)



(e) observados foram bastante semelhantes em ambas as resoluções, T126L28 e T170L42, com valores ligeiramente maiores para a análise de menor resolução. Neste caso, a porcentagem da interação total entre todos os modos horizontais (Figura 14a,b) indica núcleos de máxima interferência destrutiva de energia em torno do equador, com valores em torno de $40-50 \%$. Entre $10^{\circ} \mathrm{S}$ e $30^{\circ} \mathrm{S}$ observa-se uma faixa de interferências construtivas, com aumento de energia máximo abrangendo a região da ZCAS. Ao sul de $40^{\circ} \mathrm{S}$, os valores nulos sugerem que não há contribuições

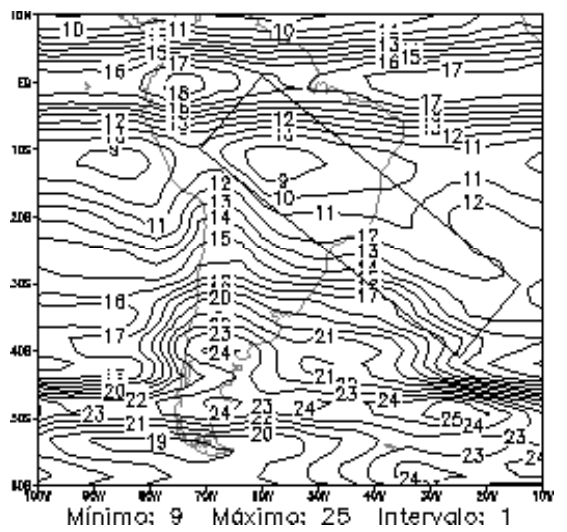

(b)

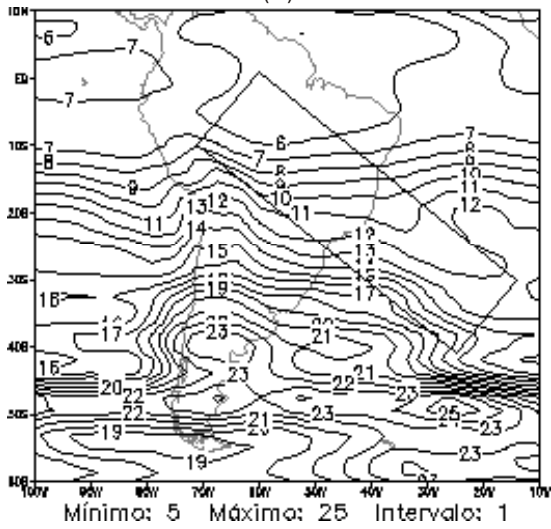

(d)

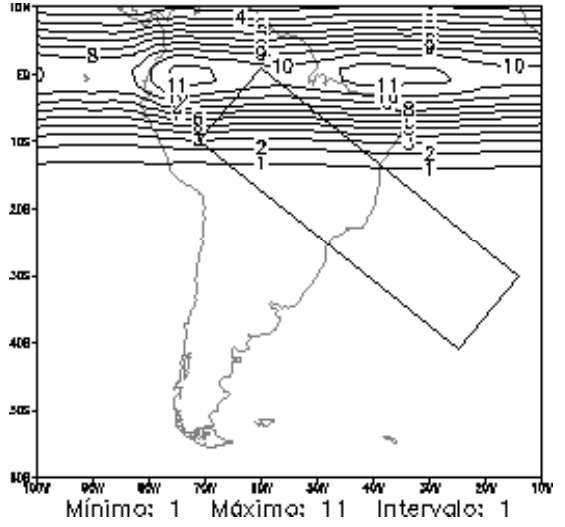

(f)

Figura 12 - Energia Total (\%) dos modos horizontais referente aos modos verticais 8 a 12 (14, para T170L42), para a análise NCEP T126L28 (a esquerda) e T170L42 (a direita): (a) e (b) Soma ; (c) e (d) Rossby; (e) e (f) Kelvin. 
devido a interação de todos os modos horizontais; pequenas interferências resultantes das interações envolvendo os modos de gravidade nesta região tendem a se cancelar. $\mathrm{O}$ confinamento das interações entre a região equatorial e tropical concorda com o fato de que os modos verticais que compõe esta categoria, são aqueles excitados pelo aquecimento convectivo, cuja resposta é baroclínica nos trópicos, gerada principalmente, pelos modos 4 e 5, como observado por Kasahara e Silva Dias (1986).

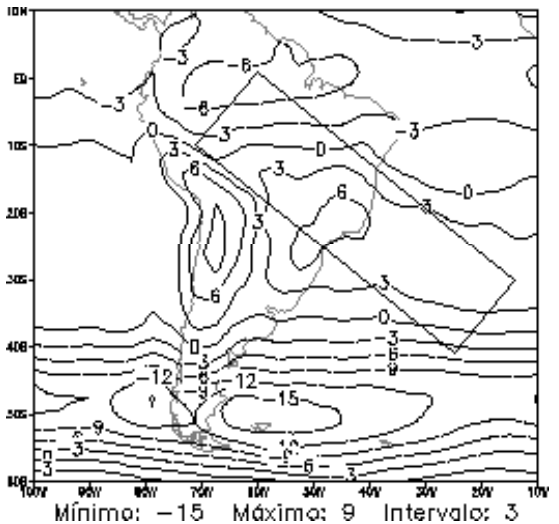

(a)

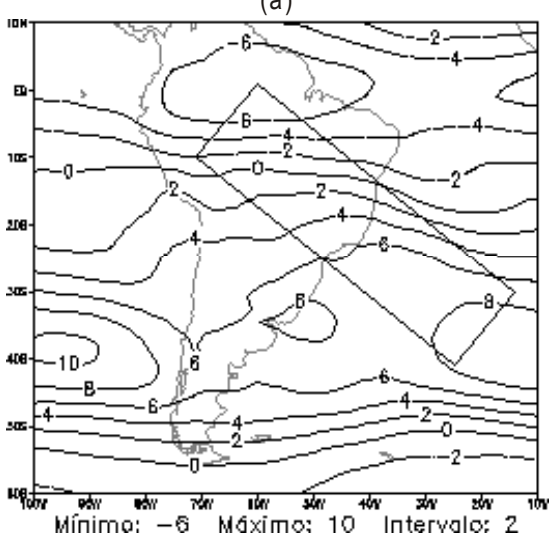

(c)

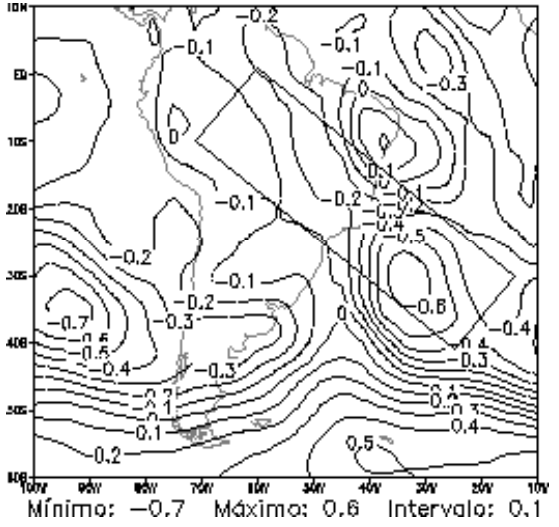

(e)
Nos painéis (c) e (d) da Figura 14, verifica-se que a interação entre os modos Rossby e Kelvin (RBKV) é a responsável pelo padrão observado no resíduo. Algumas contribuições secundárias, mas importantes para a região da ZCAS, são obtidas dos produtos cruzados Rossby-Misto, Rossby-Gravidade Oeste e Rossby-Gravidade Leste, representados na Figura 15 (a)-(f).

A interação entre os modos Rossby e Misto RossbyGravidade (Figura 15a,b) apresenta características similares

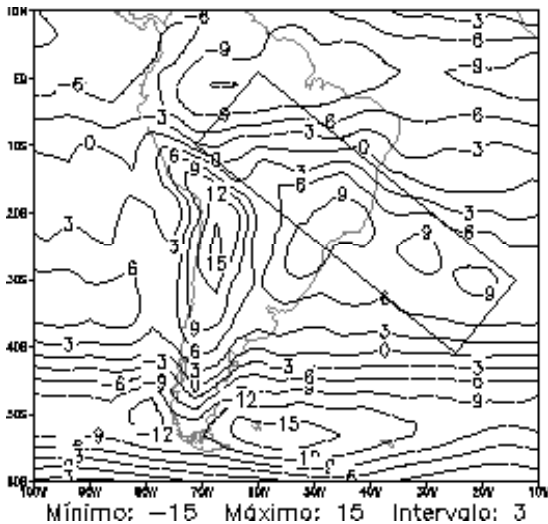

(b)



(d)

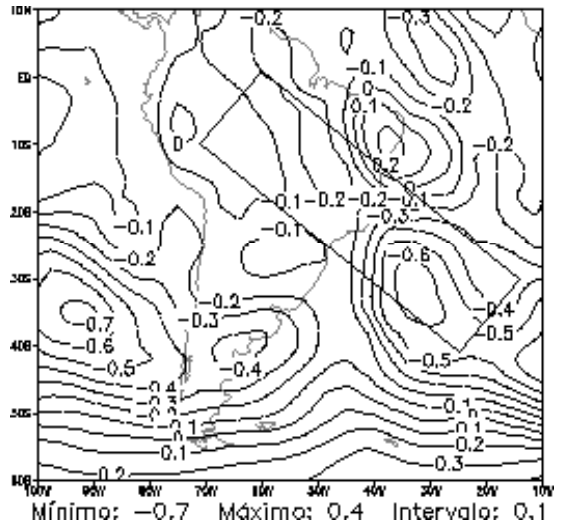

(f)

Figura 13 - Energia Total (\%) das interações entre os modos horizontais referente aos modos verticais 1 a 3, para a análise NCEP T126L28 (a esquerda) e T170L42 (a direita): (a) e (b) Resíduo; (c) e (d) Rossby-Kelvin; (e) e (f) Rossby-Misto. 
àquelas observadas na categoria I, com interferência destrutiva de energia sobre o Oceano Atlântico na região da ZCAS, e interferência construtiva de energia sobre a Região Nordeste, configurando novamente um padrão dipolo. Estes padrões parecem estar associados àqueles observados na categoria de ZCAS oceânica discutidos em Carvalho et al. (2004), nos quais se verifica uma supressão da atividade convectiva em direção ao equador do máximo de atividade convectiva e máximos de precipitação deslocados para a região Sudeste do Brasil. Além disso, dos compostos de anomalias intra-sazonais de OLR para ocorrências de ZCAS oceânicas, Carvalho et al. (2004) observaram a existência de um dipolo tropical-subtropical na atividade convectiva, o que é consistente com a análise de anomalias de altura geopotencial em $200 \mathrm{hPa}$, sugerindo que a propagação de ondas de Rossby modula a atividade convectiva da ZCAS oceânica.

Do produto cruzado RBGO (Figura $15 \mathrm{c}$,d) nota-se interferência destrutiva, com diminuição de energia sobre o continente, e construção ou aumento de energia sobre o
Oceano Atlântico. Na Figura 15e,f, nota-se um gradiente de interferências destrutivas/construtivas de energia sobre a zona de convergência, particularmente sobre o oceano, com valores máximos negativos (positivos) a oeste (leste) da posição média do composto de ZCAS, resultante da interação entre os modos Rossby e Gravidade Leste. Os resultados referentes às interações entre os modos Kelvin, Misto e Gravidade com propagação para oeste e para leste, não são discutidos nesta seção, pois são pouco expressivos na região de interesse deste estudo para esta categoria de modos verticais.

\subsection{Interação da Energia Total entre os Modos Verticais em Diferentes Níveis de Pressão}

Nesta seção é apresentada uma análise da partição vertical de energia total, destacando-se as interações entre modos verticais de cada uma das categorias, bem como o resíduo da interação de energia total entre os 12 primeiros modos verticais do modelo T126L28 e dos 14 primeiros modos verticais do

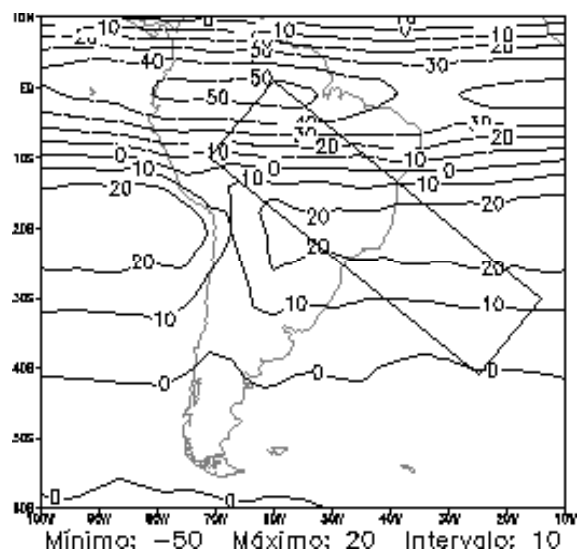

(a)

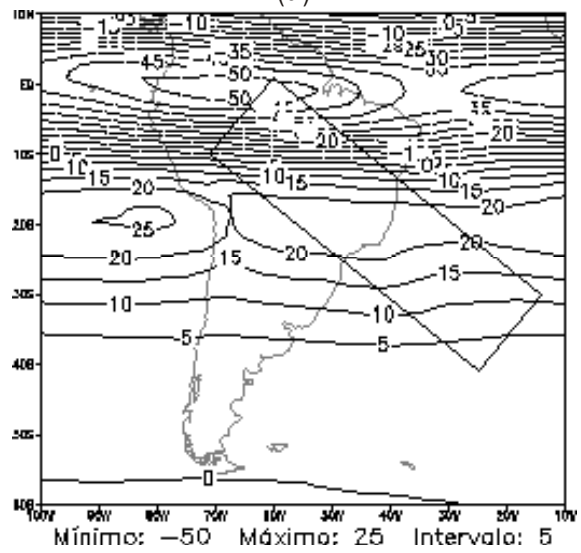

(c)

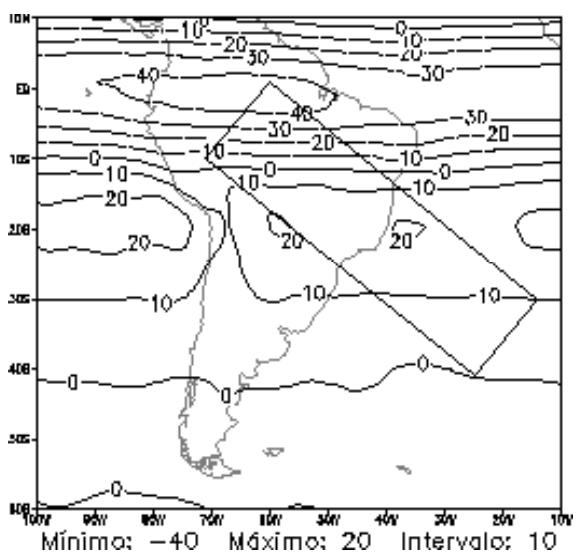

(b)

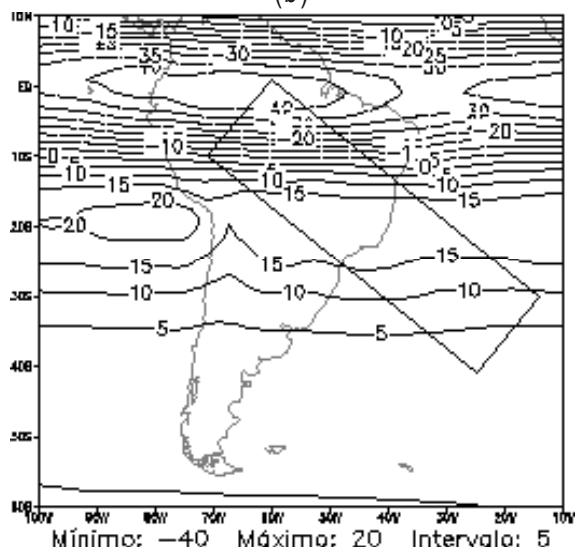

(d)

Figura 14 - Energia Total (\%) das interações entre os modos horizontais, referente aos modos verticais 4 a 7, para a análise NCEP T126L28 (a esquerda) e T170L42 (a direita): (a) e (b) Resíduo (todas as interações); (c) e (d) Rossby-Kelvin. 
modelo T170L42, considerando-se as classes de níveis de pressão descritas na Tabela 1.

Em todas as classes de níveis de pressão, as máximas porcentagens de energia total são obtidas para os modos verticais 4 a 7 , sendo observado um crescimento da energia dos baixos níveis para a estratosfera, onde os valores estão em torno de 40 a $50 \%$ na região da ZCAS. Para as categorias I e III, as distribuições de energia indicam um aumento de energia total dos baixos para os níveis médios, seguido de um decréscimo em altos níveis e máximos de energia na estratosfera, principalmente em latitudes altas, com valores da ordem de 15 a $20 \%$ para os modos verticais 1 a 3, e de 3 a 7\% para os modos verticais da categoria III. Na Figura 16, são apresentadas as porcentagens de energia total da categoria II, para os altos níveis da troposfera e para a estratosfera, respectivamente.

A interação entre modos verticais de uma mesma categoria indica que os valores mais significativos de interferência construtiva/destrutiva de energia total, também

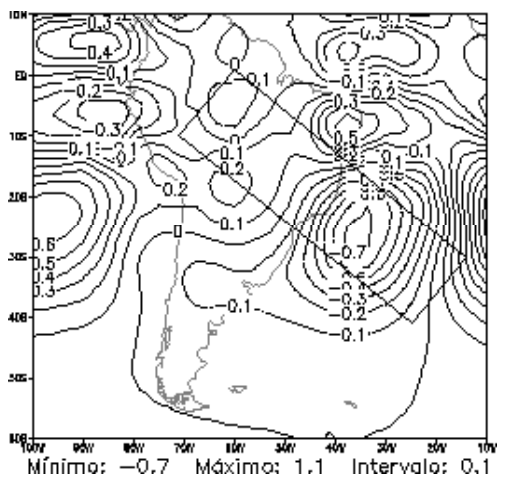

(a)

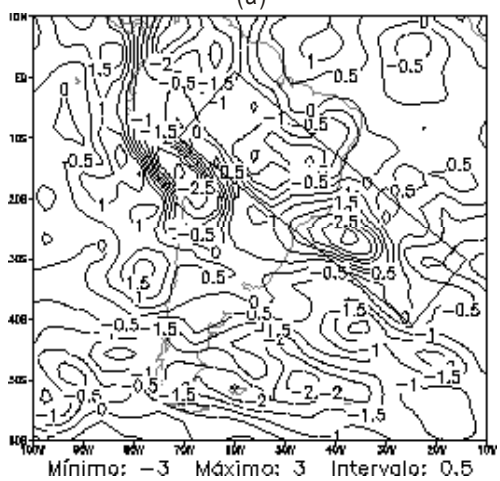

(c)

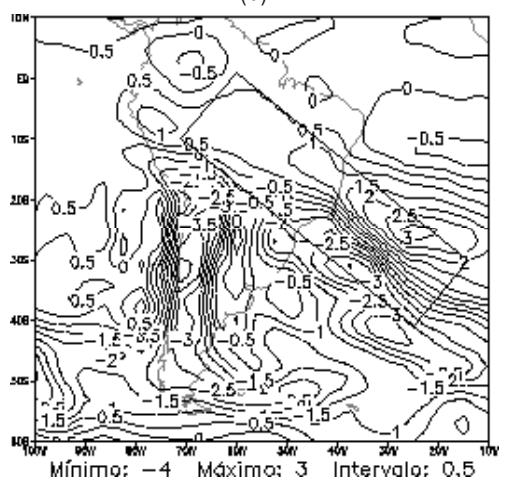

(e)

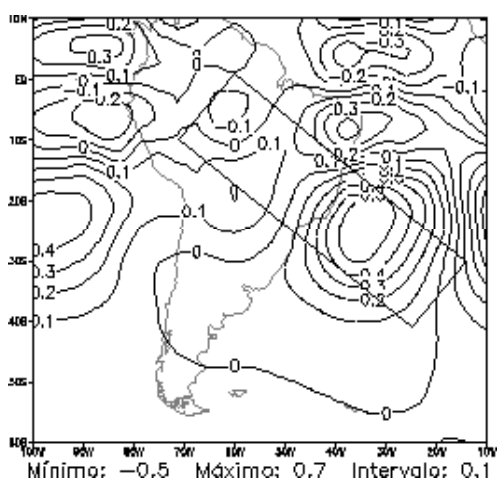

(b)

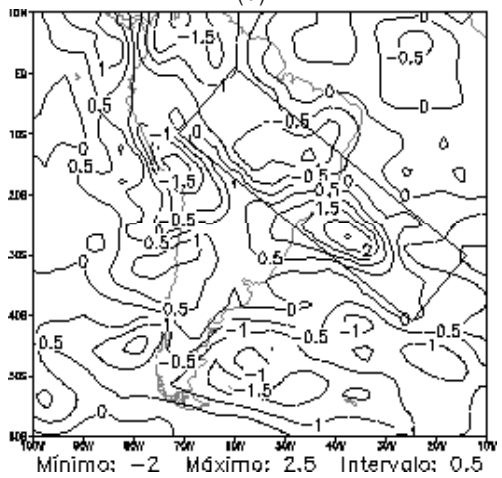

(d)

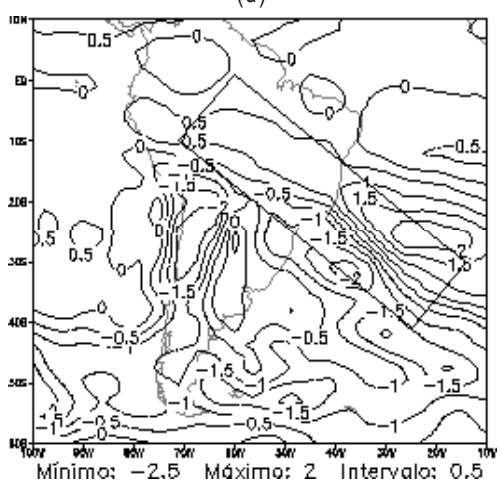

(f)

Figura 15 - Energia Total (\%) das interações entre os modos horizontais, referente aos modos verticais 4 a 7, para a análise NCEP T126L28 (a esquerda) e T170L42 (a direita): (a) e (b) Rossby-Misto; (c) e (d) Rossby-Gravidade Oeste; (e) e (f) Rossby-Gravidade Leste. 
Tabela 1 - Classes de Níveis de Pressão.

\begin{tabular}{|l|c|}
\hline \multicolumn{1}{|c|}{ Classes } & Niveis de Pressão \\
\hline a- Baixos Níveis & Superfície até $800 \mathrm{hPa}$ \\
b- Níveis Médios & $800 \mathrm{hPa}$ até $300 \mathrm{hPa}$ \\
c- Altos Níveis & $300 \mathrm{hPa}$ até $150 \mathrm{hPa}$ \\
d- Estratosfera & $150 \mathrm{hPa}$ até o Topo \\
\hline
\end{tabular}

ocorrem na categoria II, entre os modos 4 a 7 , para todas as classes de pressão, com máximos de interferências construtivas (destrutivas) de energia em torno de 20\% (em torno de 40 a $50 \%$ ), sendo observados em altos níveis (estratosfera) na região da ZCAS (Figuras 17).

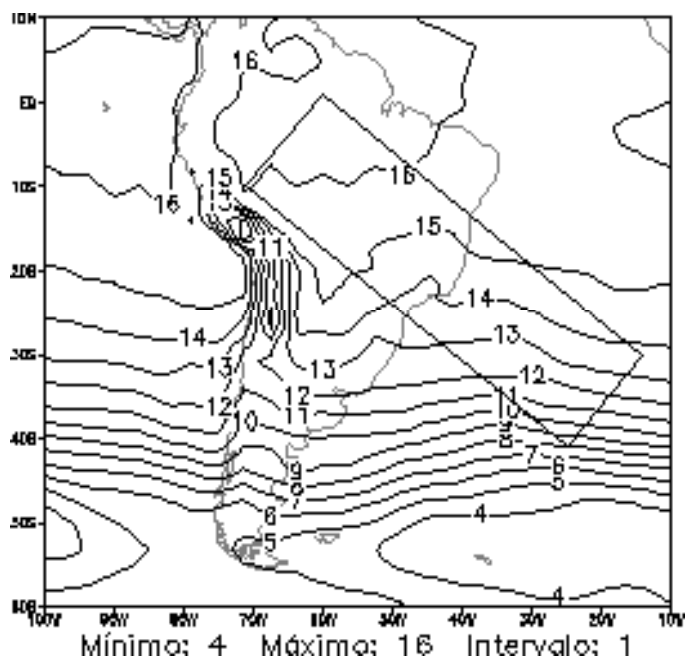

(a)

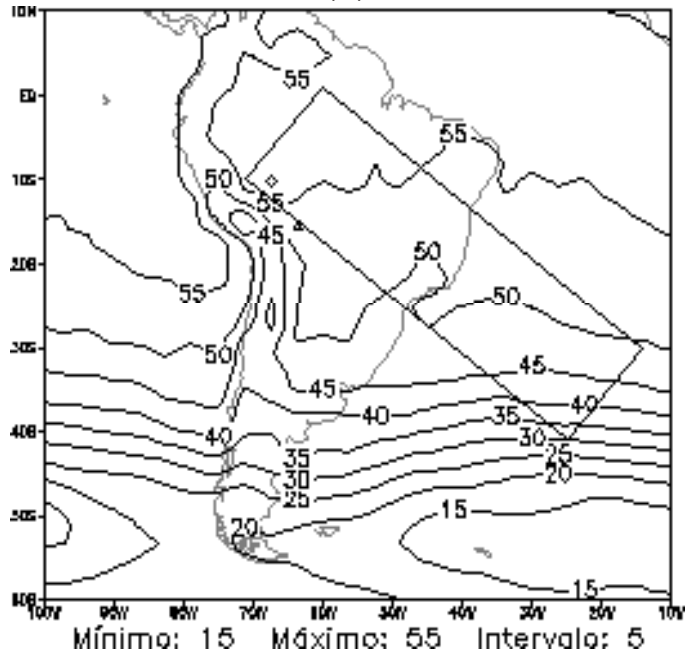

(c)
A Figura 18 ilustra os resíduos da interação de energia total entre os primeiros 12 e 14 modos verticais das análises T126L28 e T170L42, respectivamente, para as quatro classes de níveis de pressão. Em Baixos Níveis (Fig. 18a,b), nota-se valores máximos positivos na região da ZCAS em ambas as resoluções, sendo que a análise T126L28 apresenta porcentagens da ordem de três a 4 vezes maior do que aquelas obtidas com a análise T170L42. Em latitudes altas, o padrão espacial e os valores do resíduo são semelhantes em ambas as análises, notando-se máximos negativos da ordem de 10\%. Nos Níveis Médios (Fig. 18c,d), a análise T126L28 indica um padrão bem configurado sobre a região da ZCAS, com valores positivos aumentando do continente para o oceano, na direção noroeste-sudeste; valores máximos positivos são observados em latitudes altas. Para a resolução T170L42, o padrão sobre a região da ZCAS não é

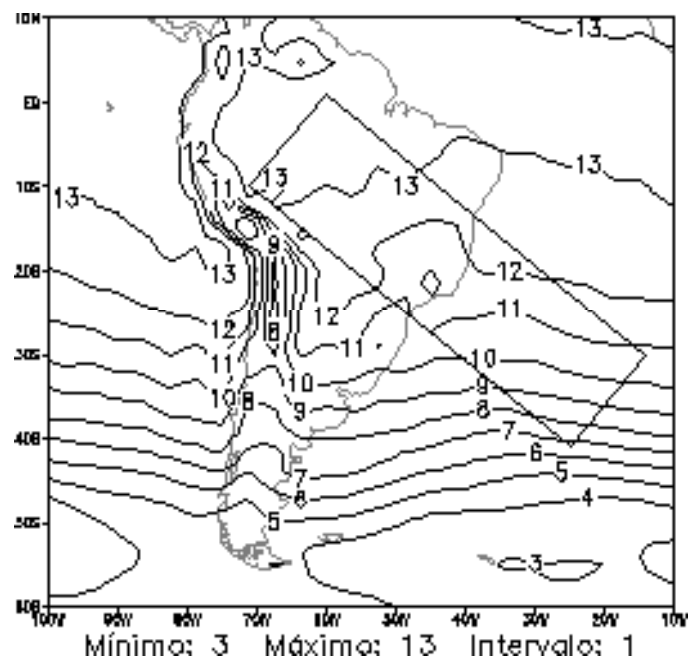

(b)

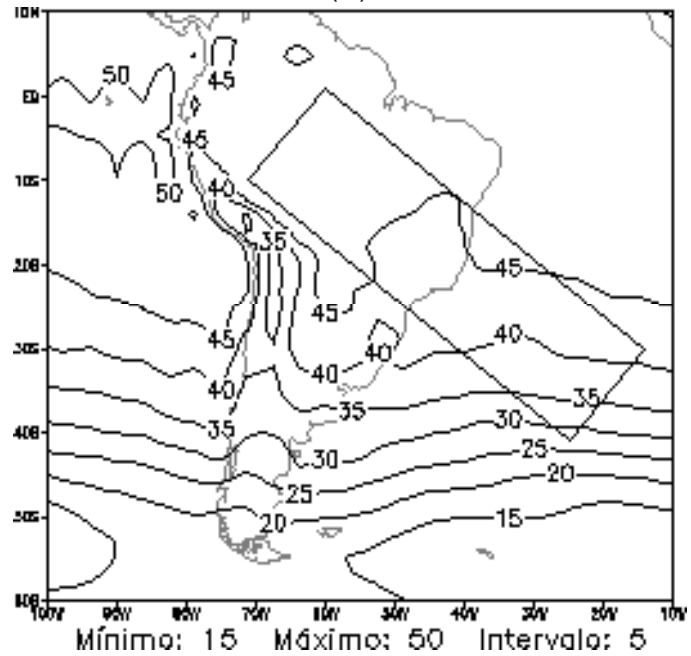

(d)

Figura 16 - Energia total (\%) dos modos verticais 4-7, análise NCEP T126L28 (a esquerda) e T170L42 (a direita): (a) e (b) Altos Níveis (300 hPa a $150 \mathrm{hPa})$ e (c) e (d) Estratosfera (150 hPa até o topo). 
bem configurado como na análise de menor resolução, embora as características gerais do campo sejam similares entre as duas análises. Resíduos com valores máximos positivos são obtidos em Altos Níveis (Fig. 18e,f), com padrão espacial e porcentagens de energia sem diferenças significativas em relação ao aumento de resolução na região da ZCAS. Em latitudes altas, verificamse porcentagens de energia maiores para a análise T126L28. $\mathrm{Na}$ Estratosfera (Fig. 18g,h) observa-se valores negativos de resíduo em toda a região da América do Sul, que tendem a compensar a partição de energia entre os níveis troposféricos. As máximas porcentagens de energia estão localizadas sobre a região da ZCAS, sendo os valores mais elevados para a resolução T126L28.

Das Figuras 9 e 18 é possível observar também que a maior interação entre os modos aparece justamente na região onde a fonte de calor é mais intensa, ou seja, em latitudes mais altas, configurando a ZCAS oceânica, discutida em Carvalho et al. (2004). Um outro máximo é também verificado na região da ITCZ. Este fato está associado à interação local entre os modos verticais, em particular à interação dos modos internos 4 a 7 , que se processam na região da fonte de calor (Figura não apresentada). Nota-se que este é um efeito devido, provavelmente, à interação através das ondas de gravidade geradas pela fonte de calor (Figuras não apresentadas).

\section{CONCLUSÕES}

A análise observacional da energética durante eventos de ZCAS indica que a maior parte da energia total está concentrada nos 7 primeiros modos verticais, com os modos internos 4 a 7 ,

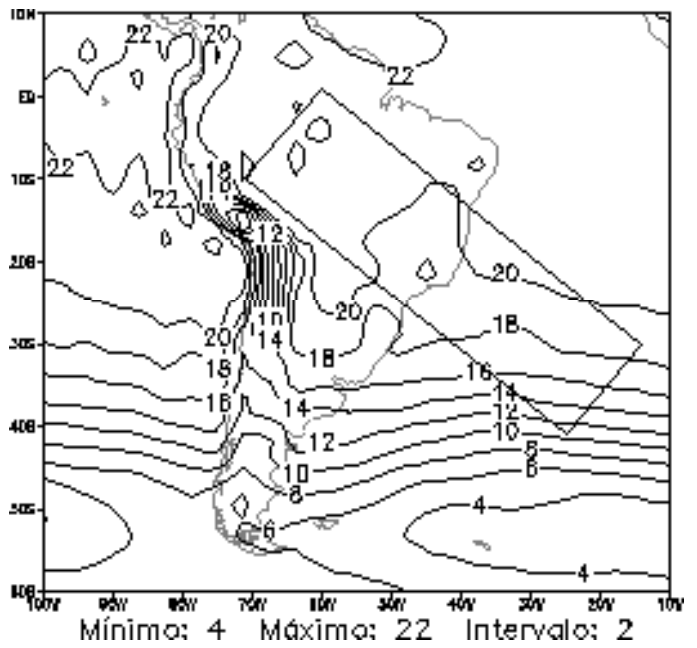

(a)

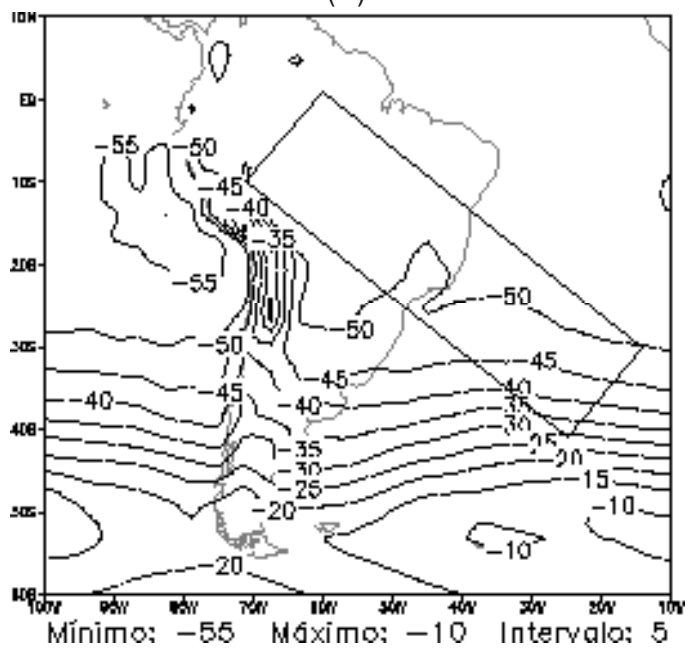

(c)

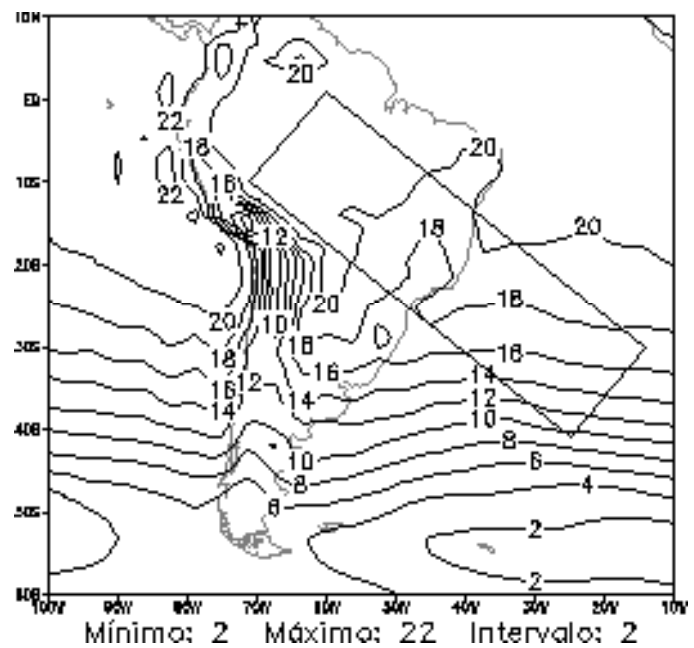

(b)

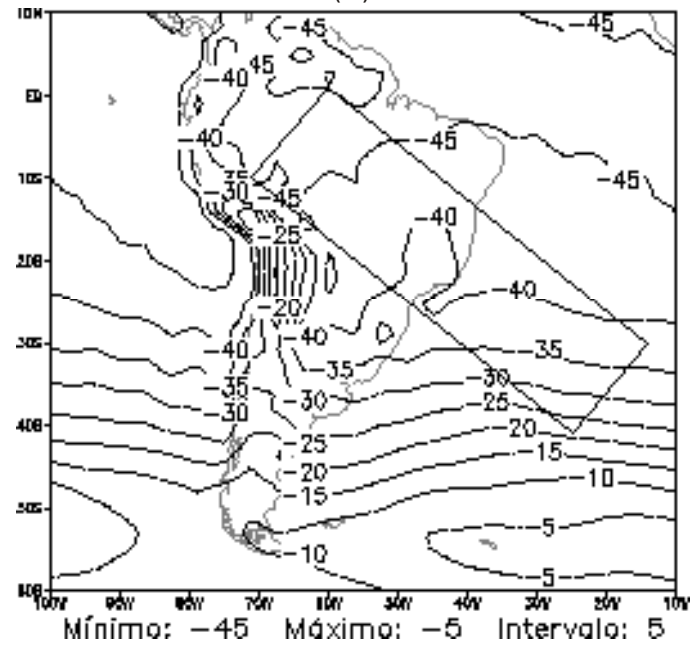

(d)

Figura 17 - Interação Energia Total (\%)entre os modos verticais 4 a 7, análise NCEP T126L28 (a esquerda) e T170L42 (a direita): (a) e (b) Altos Níveis (300 hPa a $150 \mathrm{hPa}$ ) e (c) e (d) Estratosfera (150 hPa até o topo). 

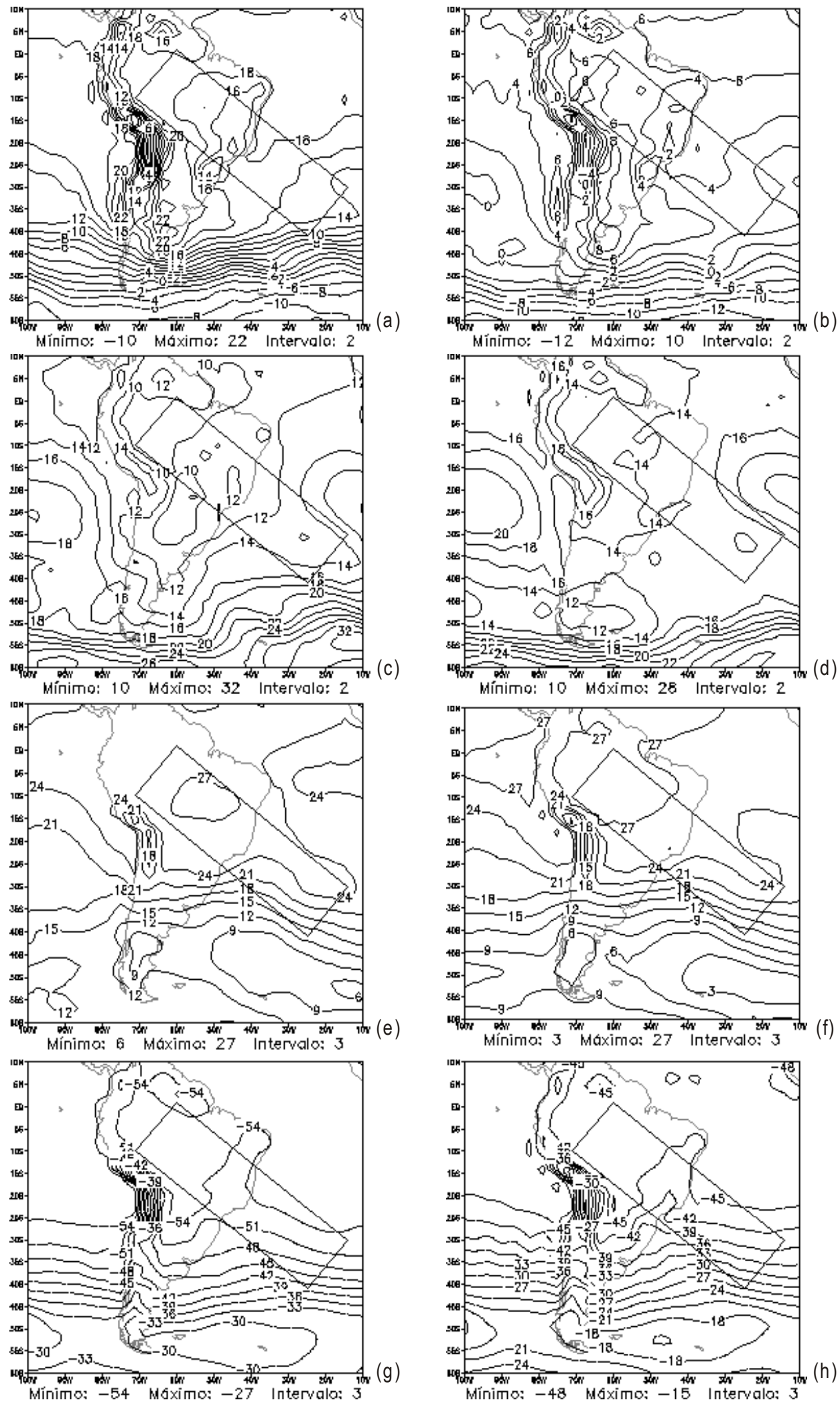

Figura 18 - Resíduo da Interação Energia Total (\%), modos verticais 1 a 12 - análise NCEP T126L28 (a esquerda) e 1 a 14 - análise T170L42 (a direita): (a) e (b) Baixos Níveis; (c) e (d) Níveis Médios; (e) e (f) Altos Níveis; e (g) e (h) Estratosfera. 
com alturas equivalentes entre 100 e $600 \mathrm{~m}$, apresentando as maiores porcentagens de energia total, com valores em torno de $60 \%$. Um máximo secundário de porcentagem de energia total foi observado para os modos verticais da categoria I, que inclui o modo externo. A partição de energia do modelo nas formas cinética (ECn) e energia potencial (EPn), bem como a contribuição percentual de energia total em função dos modos verticais mostram que a energia cinética parece ser, em grande parte, representada pelos modos verticais 1 a 3 , enquanto a energia potencial do modo externo é mínima, com um pico acentuado no modo interno $\mathrm{n}=5$, com altura equivalente de $284 \mathrm{~m}$ e $342 \mathrm{~m}$, respectivamente, para os modelos de 28 e 42 níveis, o qual determina a dominância na distribuição da porcentagem de energia. Estes resultados estão de acordo com os trabalhos de Kasahara e Puri (1981) e Silva Dias e Bonatti (1985).

Os campos de porcentagem de energia total para as análises do NCEP T126L28 e T170L42 mostram padrões bastante semelhantes para ambas as resoluções, notandose apenas algumas diferenças quantitativas. Os valores apresentados pela análise com maior resolução são ligeiramente inferiores àqueles da análise T126L28 para os modos verticais 1 a 3 (categoria I) e 4 a 7 (categoria II); o inverso é verificado para a categoria III, que inclui os modos 8 a 12 (14, para T170L42), ressaltando o impacto do aumento da resolução vertical, de 28 para 42 níveis. Isto está associado ao fato de que a discretização vertical do modelo de 42 níveis pode realçar e/ou definir melhor a partição de energia, incluindo aspectos da energética não capturados pelo modelo de 28 níveis.

Além disso, verificou-se que a energia dos modos verticais 1 a 3 é mais significativa em latitudes mais altas, diminuindo em direção ao equador, o que pode estar associado à influência do jato subtropical, uma vez que este pode ser descrito por ondas de Rossby longas. Os modos internos 4 a 7 apresentaram valores maiores de energia em grande parte da faixa central da América do Sul e próximo ao equador, incluindo a região da ZCAS, com núcleos de máxima porcentagem de energia situados em regiões convectivamente ativas, e em concordância com o posicionamento da banda de nebulosidade associada a ZCAS e com a localização das fontes de energia, bem definidas sobre a região da ZCAS e da ZCIT. Para a categoria III, os resultados foram semelhantes àqueles obtidos para os modos verticais $1 \mathrm{a}$ 3 , entretanto com menores porcentagens de energia total.

A partição de energia entre os modos horizontais foi avaliada considerando as auto-interações e as interações entre diferentes modos horizontais. No caso das auto-interações, a análise energética indicou que, em ambas as resoluções, T126L28 e T170L42, as porcentagens de energia foram bem distribuídas entre as três categorias de modos verticais, destacando-se os modos Rossby e Kelvin, como os principais determinantes do padrão espacial da energia total. Já as interações entre pares de modos horizontais indicaram contribuições relevantes para a energéticas nas duas primeiras categorias de modos verticais, 1 a 3 e 4 a 7 . O resíduo, ou soma de todas as interações, apontou maiores interferências construtivas/destrutivas de energia para os modos internos 4 a 7, sendo o produto cruzado dos modos Rossby e Kelvin o principal responsável pelo padrão observado em todas as categorias de modos verticais.

Estes resultados têm algumas implicações importantes para a previsão climática, pois sugerem que a resolução vertical pode ser importante para a correta representação nos modelos, de padrões de teleconexões associados com a ZCAS, uma vez que as conversões de energia dos modos internos (que requerem uma maior resolução vertical) para o modo externo na região convectiva podem ser importantes para a excitação das ondas com estruturas verticais mais barotrópicas que, por sua vez, são importantes para o desenvolvimento dos padrões globais de teleconexões.

Valores máximos de porcentagem de energia total foram obtidos para os modos verticais 4 a 7 , em todas as classes de níveis de pressão, sendo observado um crescimento da energia dos Baixos Níveis para a Estratosfera, onde os valores estiveram em torno de 40 a 50\% na região da ZCAS. Os valores mais significativos de interferência construtiva/destrutiva de energia total resultam também da interação entre os modos 4 a 7, em todas as classes de níveis de pressão, notando-se máxima construção (destruição) de energia em Altos Níveis (Estratosfera).

Os resíduos da interação de energia total entre os primeiros 12 e 14 modos verticais da análise T126L28 e T170L42, apresentaram valores positivos em Baixos, Médios e Altos Níveis, e valores negativos na Estratosfera, que tendem a compensar a partição de energia entre os níveis troposféricos. Valores ligeiramente maiores são obtidos para a resolução T126L28, principalmente em Baixos Níveis e Estratosfera. A maior interação entre os modos é observada sobre a região onde a fonte de calor é mais intensa, o que está associado à interação local entre os modos verticais, principalmente entre os modos internos 4 a 7, e que provavelmente é devido à interação de ondas de gravidade geradas a partir da fonte de calor.

\section{AGRADECIMENTOS}

Os autores agradecem aos revisores da RBMET, Dr. Pedro Leite da Silva Dias e um revisor anônimo, pelos comentários e sugestões, importantes para o aprimoramento científico deste trabalho. Os autores foram parcialmente financiados pela Coordenação de Aperfeiçoamento de Nível Superior (CAPES). Este trabalho é parte da tese de doutorado do primeiro autor. 


\section{REFERÊNCIAS BIBLIOGRÁFICAS}

ANDRADE, C.R. Análise das trocas de energia entre modos verticais e horizontais em resposta a fontes tropicais de calor de grande escala. (INPE-5681-TDI/567) Dissertação (Mestrado em Meteorologia) - Instituto Nacional de Pesquisas Espaciais, São José dos Campos, 366 f, 1994.

CARVALHO, L.M.V.; JONES, C.; LIEBMANN B. The South Atlantic Convergence Zone: Intensity, Form, Persistence, and Relationships with Intraseasonal to Interannual Activity and Extreme Rainfall. J. Climate, v. 17, n.1, p.88-108, 2004.

CLIMANÁLISE - Boletim de Monitoramento e Análise Climática, v.16, n.01, jan, 2001a. Disponível em: <http:// www.cptec.inpe.br/products/climanalise/0101/index.html $>$. Acesso em: 17 mar 2003.

CLIMANÁLISE - Boletim de Monitoramento e Análise Climática, v.16, n.11, nov, 2001b. Disponível em: $<$ http:// www.cptec.inpe.br/products/climanalise/1101/index.html $>$. Acesso em: 17 mar 2003.

CLIMANÁLISE - Boletim de Monitoramento e Análise Climática, v.16, n.12, dez, 2001c. Disponível em: <http:// www.cptec.inpe.br/products/climanalise/1201/index.html $>$. Acesso em: 17 mar 2003.

CLIMANÁLISE - Boletim de Monitoramento e Análise Climática, v.17, n.02, fev, 2002. Disponível em: <http:// www.cptec.inpe.br/products/climanalise/0202/index.html $>$. Acesso em: 17 mar 2003.

GANDU, A.W. Modelagem numérica da resposta troposférica regional à fontes tropicais de calor. Tese (Doutorado em Meteorologia) - Departamento de Ciências Atmosféricas do Instituto Astronômico e Geofísico, Universidade de São Paulo, São Paulo, 209 f, 1993.

GRIMM, A.M.; SILVA DIAS, P.L. Analysis of tropicalextratropical interactions with influence functions of a barotropic model. J. Atmos. Sci., v. 52, n. 20, p. 3538-3555, 1995.

KASAHARA, A.; PURI, K. Spectral representation of threedimensional global data by expansion in normal mode functions. Mon. Wea. Rev., v. 109, n. 1, p. 37-51, 1981.

KASAHARA, A.; SILVA DIAS, P.L. Response of planetary waves to stationary tropical heating in a global atmosphere with meridional and vertical shear. J. Atmos. Sci., v. 43, n. 18, p. 1893-1911, 1986.

KASAHARA, A.; TANAKA, H.L. Application of Vertical Normal Mode Expansion to Problems of Baroclinic Instability. J. Atmos. Sci., v. 46, n. 4, p.489-510, 1989.

KO, S.D.; TRIBBIA J.J.; BOYD, J.P. Energetics analysis of a multilevel global spectral model. Part I: balanced energy and transient energy. Mon. Wea. Rev., v. 117, n. 9, p. 19411953, 1989.

MENDONÇA, R.W.B. Estudo das trocas horizontais e verticais de energia durante episódios de ZCAS: influência da resolução das análises e dos modelos e da parametrização de convecção. (INPE-14213-TDI/1114) Tese (Doutorado em Meteorologia) - Instituto Nacional de Pesquisas Espaciais, São José dos Campos, 204p, 2005.

PURI, K. The relationship between convective adjustment, Hadley circulation and normal modes of the ANMRC spectral model. Mon. Wea. Rev., v. 111, n. 1, p. 23-33, 1983.

RANDEL, W.J.; STANFORD, J.L. An observational study of medium-scale wave dynamics in the Southern Hemisphere summer. Part I: Wave structure and energetics. J. Atmos. Sci., v. 42, n. 11, p. 1172-1187, 1985a.

RANDEL, W.J.; STANFORD, J.L. The observed life cycle of a Baroclinic Instability. J. Atmos. Sci., v. 42, n. 13, p. 1364-1373, $1985 b$.

RAUPP, C.F.M.; SILVA DIAS, P.L. Efeitos de processos não lineares sobre a influência inter-hemisférica de fontes tropicais de calor. In: Anais do XII Congresso Brasileiro de Meteorologia - A Meteorologia e a Gestão de Energia. 1 CD-ROM, Foz do Iguaçu PR: Sociedade Brasileira de Meteorologia, 2002.

SILVA DIAS, P.L.; BONATTI, J.P. A preliminary study of the observed vertical mode structure of the summer circulation over tropical South America. Tellus, v. 37A, n. 2, p. 185$195,1985$.

SILVA DIAS, P.L.; BONATTI, J.P. Vertical mode decomposition and model resolution. Tellus, v. 38A, n. 3, p. 205-214, 1986.

SILVA DIAS, P.L.; BONATTI, J.P.; KOUSKY, V.E. Diurnally forced tropical tropospheric circulation over South America. Mon. Wea. Rev., v. 115, n. 8, p. 1465-1478, 1987. 